\title{
A remarkably stable kissing-loop interaction defines substrate recognition by the Neurospora Varkud Satellite ribozyme
}

\author{
PATRICIA BOUCHARD and PASCALE LEGAULT \\ Département de Biochimie et Médecine Moléculaire, Université de Montréal, C.P. 6128, Succursale Centre-Ville, Montréal, QC, Canada H3C 3J7
}

\begin{abstract}
Kissing loops are tertiary structure elements that often play key roles in functional RNAs. In the Neurospora VS ribozyme, a kissingloop interaction between the stem-loop I (SLI) substrate and stem-loop V (SLV) of the catalytic domain is known to play an important role in substrate recognition. In addition, this I/V kissing-loop interaction is associated with a helix shift in SLI that activates the substrate for catalysis. To better understand the role of this kissing-loop interaction in substrate recognition and activation by the VS ribozyme, we performed a thermodynamic characterization by isothermal titration calorimetry using isolated SLI and SLV stem-loops. We demonstrate that preshifted SLI variants have higher affinity for SLV than shiftable SLI variants, with an energetic cost of $1.8-3 \mathrm{kcal} / \mathrm{mol}$ for the helix shift in SLI. The affinity of the preshifted SLI for SLV is remarkably high, the interaction being more stable by 7-8 $\mathrm{kcal} / \mathrm{mol}$ than predicted for a comparable duplex containing three Watson-Crick base pairs. The structural basis of this remarkable stability is discussed in light of previous NMR studies. Comparative thermodynamic studies reveal that kissing-loop complexes containing 6-7 Watson-Crick base pairs are as stable as predicted from comparable RNA duplexes; however, those with 2-3 Watson-Crick base pairs are more stable than predicted. Interestingly, the stability of SLI/ribozyme complexes is similar to that of SLI/SLV complexes. Thus, the I/V kissing loop interaction represents the predominant energetic contribution to substrate recognition by the trans-cleaving VS ribozyme.
\end{abstract}

Keywords: Neurospora VS ribozyme; substrate recognition; U-turn; kissing-loop interaction; isothermal titration calorimetry

\section{INTRODUCTION}

Kissing-loop interactions are widespread elements of RNA tertiary structures that result from base-pairing between the terminal loops of two hairpins. Their formation is central to many RNA-mediated processes, such as antisense recognition, plasmid replication control, retroviral dimerization, translation initiation, and ribosomal frameshifting (Wagner and Simons 1994; Guo et al. 2001; Brunel et al. 2002; Baranov et al. 2005; Brantl 2007). One of the best-studied kissing-loop interactions occurs during retroviral genome dimerization in HIV-1, where it forms between palindromic base sequences of the dimer initiation site (Skripkin et al. 1994; Ennifar et al. 2001; Brunel et al. 2002). Although kissing loops form long-range interactions between different RNAs or remote domains within the same RNA, they also play important roles in stabilizing the complex architecture of functional RNA elements, such as tRNAs (Quigley and Rich 1976) riboswitch aptamers (Batey et al. 2004; Serganov et al. 2004, 2008; Lemay et al. 2006; Blouin and Lafontaine 2007; Garst et al. 2008), and ribozymes (De la Peña et al. 2003; Khvorova et al.

Corresponding author: pascale.legault@umontreal.ca

Article published online ahead of print. Article and publication date are at http://www.rnajournal.org/cgi/doi/10.1261/rna.046144.114.
2003; Chi et al. 2008; Dufour et al. 2009). Thus, kissingloop motifs play crucial roles in RNA structure and function; however, only a few of these have been thermodynamically characterized.

Like several other functional RNAs, the Neurospora VS ribozyme depends on the formation of a kissing-loop interaction. Early work on the self-cleaving VS ribozyme revealed that the catalytic domain (VS Rz) recognizes its substrate (stem-loop I) through a kissing-loop interaction that is stabilized by magnesium ions (Fig. 1A; Beattie et al. 1995; Rastogi et al. 1996). This interaction involves three Watson-Crick (W-C) base pairs between residues 630, 631, and 632 of stem-loop I (SLI) and residues 697, 698, and 699 of stemloop V (SLV). It is required for proper folding (Andersen and Collins 2001; Hiley and Collins 2001) as well as for the efficient phosphodiester bond cleavage between G620 and A621 and the reverse ligation reaction (Rastogi et al. 1996; Andersen and Collins 2000). Interestingly, formation of the $\mathrm{I} / \mathrm{V}$ kissing-loop interaction involves a well-characterized

(C) 2014 Bouchard and Legault This article is distributed exclusively by the RNA Society for the first 12 months after the full-issue publication date (see http://rnajournal.cshlp.org/site/misc/terms.xhtml). After 12 months, it is available under a Creative Commons License (Attribution-NonCommercial 4.0 International), as described at http://creativecommons.org/licenses/bync/4.0/. 
A

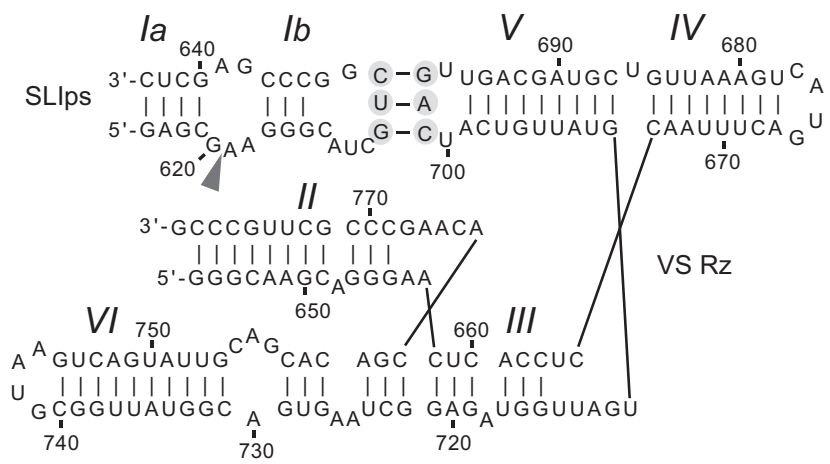

B
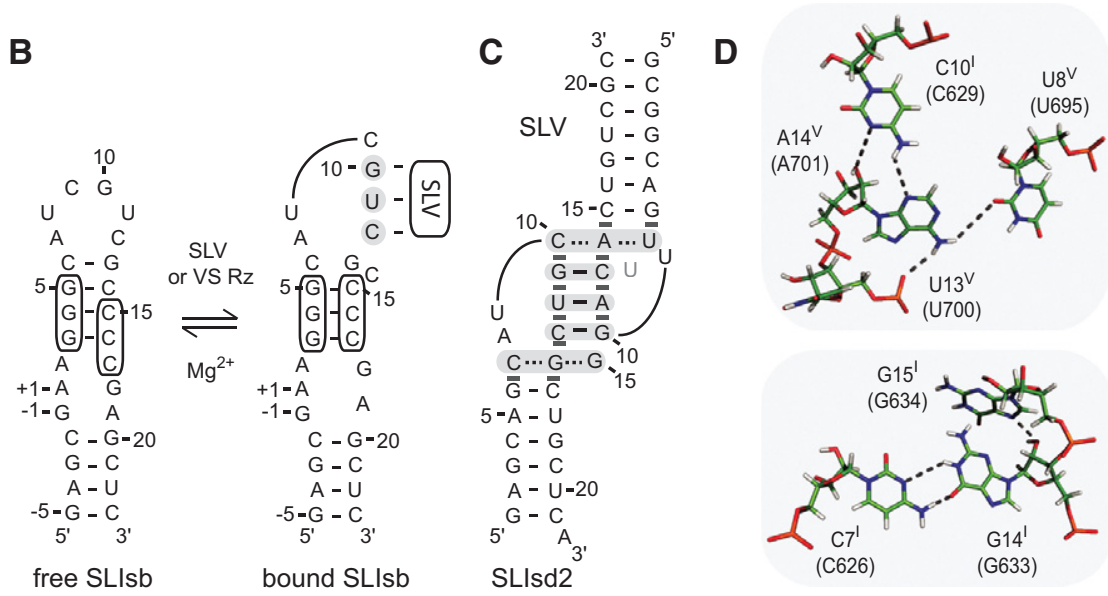

FIGURE 1. Primary and secondary structures of the Neurospora VS ribozyme. (A) The catalytic domain of the VS ribozyme containing helical domains II-VI (VS Rz) and an SLI substrate (SLIps) containing stems Ia and Ib. The cleavage site is indicated by an arrowhead. The I/V kissing-loop interaction involves W-C base pairs (black lines) between shaded residues of SLI and SLV (Beattie et al. 1995; Rastogi et al. 1996). (B) Formation of the I/V kissing-loop is accompanied by a structural rearrangement of the SLI substrate from an unshifted (free) to a shifted (bound) conformation. The cleavage site is between residues -1 and +1 of SLIsb. $(C, D)$ Structural characteristics of the I/V kissing-loop based on the NMR structure of the SLIds2/SLV complex (Bouchard and Legault 2014). In $C, \mathrm{~W}-\mathrm{C}$ and noncanonical base pairs are represented by solid and dashed lines, respectively, on the secondary structure of the complex, whereas stable base stacking at the kissing-loop junction is illustrated by gray rectangles. U13 is in gray to illustrate its extrusion from the loop $\mathrm{V}$ fold. In $D$, hydrogen bonds within the base triples of the minimized averaged structure are represented by dotted lines.

conformational change in SLI from an unshifted to a shifted conformation (Fig. 1B; Andersen and Collins 2000, 2001; Michiels et al. 2000; Flinders and Dieckmann 2001; Hoffmann et al. 2003), and either the catalytic domain or an isolated SLV can produce this helix shift within the SLI substrate (Andersen and Collins 2000). Through the SLI helix shift, the I/V kissing-loop interaction activates the substrate for catalysis, since ribozymes containing SLI variants that stabilized the unshifted conformation are inactive, whereas those that allow or favor the shifted conformation (preshifted substrates) are active (Andersen and Collins 2000). Formation of the I/V kissing-loop interaction also facilitates docking of the cleavage site internal loop of SLI with the A730 loop of SLVI (Andersen and Collins 2001; Hiley and Collins 2001; Hiley et al. 2002). Our current understanding is that the internal loops of SLI and SLVI must precisely interact to create the active site, where the nucleobases of G638 and
A756 play key roles in the general acidbase cleavage mechanism (Lafontaine et al. 2001b, 2002b; Sood and Collins 2002; Jones and Strobel 2003; Zhao et al. 2005; Smith and Collins 2007; Wilson et al. 2007, 2010; Jaikaran et al. 2008). Thus, the I/V kissing-loop interaction is important for several steps of the VS ribozyme cleavage reaction, including substrate recognition, activation, and docking for catalysis.

Until recently, structural insights into the I/V kissing-loop interaction were provided by three-dimensional models of the full ribozyme (Hiley and Collins 2001; Lafontaine et al. 2001a, 2002a; Lipfert et al. 2008) as well as high-resolution NMR structures of free SLV (Campbell and Legault 2005; Campbell et al. 2006) and of the unshifted and shifted conformations of SLI (Michiels et al. 2000; Flinders and Dieckmann 2001; Hoffmann et al. 2003). As part of our efforts to characterize the I/V kissing-loop interaction, we previously reported a structure-function study that addressed the role of loop $\mathrm{V}$ residues in SLI substrate recognition (Bouchard et al. 2008). One intriguing observation is that, although any base can replace the extruded U700 loop residue, deletion of this nucleotide substantially reduces ribozyme cleavage activity (Bouchard et al. 2008), possibly by affecting substrate binding. More recently, we performed NMR studies of several SLI/SLV complexes formed with RNA hairpins derived from the VS ribozyme and determined the NMR structure of an SLI/SLV kissing-loop complex (Bouchard and Legault 2014). These NMR studies provide clear structural evidence for the helix shift in SLI upon SLV binding. In addition, the NMR structure of an SLI/SLV complex confirms that both the SLI and SLV loops adopt U-turn structures, which facilitate formation of the three expected W-C base pairs between SLI and SLV, and additional hydrogen bonding and base stacking interactions at the kissing-loop junction (Fig. 1C,D). Complementary thermodynamic investigations of the $\mathrm{I} / \mathrm{V}$ kissing-loop interaction are needed to evaluate the affinity of the SLI/SLV interaction in light of the NMR structure and to help understand the effect of SLI and SLV sequence variations on substrate recognition and catalysis.

Binding studies have been previously carried out using various SLI substrates and a trans-cleaving VS ribozyme (Zamel and Collins 2002). Although these studies revealed the importance of the shifted SLI conformation in facilitating 
binding to the ribozyme (Zamel and Collins 2002), it used a ribozyme system stabilized by an artificial intermolecular stem and thus yielded $K_{D}$ values that do not directly reflect the stability of the I/V kissing loop (Zamel and Collins 2002). In the present work, we use isothermal titration calorimetry (ITC) (Reymond et al. 2009; Salim and Feig 2009) to thermodynamically characterize the I/V kissing-loop interaction formed between isolated SLI and SLV hairpins. As a result, our study provides $K_{D}$ values as well as energetic contributions directly associated with formation of the I/V kissing-loop interaction. In addition, since most of the SLI/ SLV complexes investigated here have been structurally characterized by NMR spectroscopy (Bouchard et al. 2008; Bouchard and Legault 2014), the thermodynamic parameters can be directly related to structural features of SLI/SLV complexes. In particular, we examine the effect of kinetically characterized SLV sequence variations on the thermodynamic parameters associated with the I/V kissing-loop interaction. We also investigate the thermodynamic contribution of the helix shift in SLI on the stability of SLI/SLV complexes using several shiftable, preshifted, and double-stranded SLI variants. Finally, using noncleavable SLI substrates, we compare the affinity of SLI/SLV complexes with that of SLI/ribozyme complexes to evaluate the relative contribution of the I/V kissing-loop interaction to substrate recognition in the VS ribozyme.

\section{RESULTS}

\section{Thermodynamic characterization of the VS ribozyme I/V kissing-loop interaction}

To better understand substrate recognition by the VS ribozyme, we determined the thermodynamic parameters associated with the I/V kissing-loop interaction by ITC using two isolated stem-loops derived from the VS ribozyme: the SLI substrate and the SLV receptor (Fig. 2). Biophysical characterization of the I/V kissing-loop interaction using isolated RNA stem-loops is justified by the fact that an isolated SLV receptor hairpin is sufficient to bind an isolated SLI substrate and cause the same helix shift in SLI that is observed with the full VS ribozyme catalytic domain (Andersen and Collins 2001; Bouchard et al. 2008; Bouchard and Legault 2014). To further simplify the thermodynamic characterization of the I/V kissing-loop interaction, the initial SLI substrate was designed to adopt only an active preshifted conformation (SLIps) (Fig. 2A; Andersen and Collins 2000; Zamel and Collins 2002). The same SLIps sequence was previously used for kinetic characterization of VS ribozyme variants (Bouchard et al. 2008). Using NMR spectroscopy and native gel electrophoresis, we previously verified that both SLIps and SLV RNAs form stable hairpins under conditions used for ITC studies (Bouchard et al. 2008; Bouchard and Legault 2014). NMR spectroscopy studies also indicate that SLIps and SLV form a stable 1:1 kissing-loop complex in the presence of
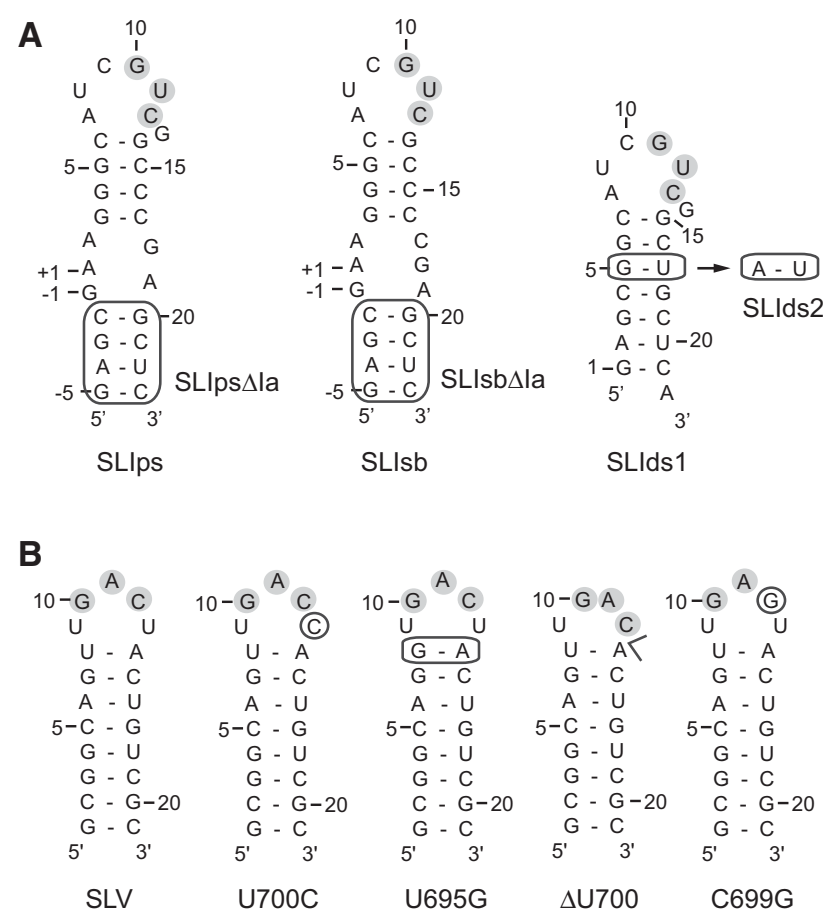

FIGURE 2. Primary and secondary structures of SLI and SLV RNAs used in this study. (A) The SLIps substrate RNA and related variants. SLIps $\Delta \mathrm{Ia}$ and SLIsb $\Delta \mathrm{Ia}$ are derivatives of SLIps and SLIsb, respectively, in which stem Ia is absent (boxed region). SLIsd2 is a G5A variant of SLIds1. The VS ribozyme cleavage site for SLIps, SLIps $\Delta$ Ia, SLIsb, and SLIsb $\Delta \mathrm{Ia}$ is between residues -1 and +1 of SLI. (B) The wild-type SLV RNA and related SLV variants. In $A$ and $B$, residues that participate in the three $\mathrm{W}-\mathrm{C}$ base pairs at the I/V kissing-loop junction are shaded in gray.

$\mathrm{MgCl}_{2}$ (Bouchard and Legault 2014). ITC experiments were first carried out at $25^{\circ} \mathrm{C}$ in a buffer containing $20 \mathrm{mM}$ $\mathrm{MgCl}_{2}$ (Fig. 3). Analysis of duplicate ITC experiments for formation of this 1:1 SLIps/SLV complex yields the following average thermodynamic values: $K_{D}=0.24 \pm 0.01 \mu \mathrm{M} ; \Delta H=$ $-22.0 \pm 0.1 \mathrm{kcal} / \mathrm{mol} ; \quad-T \Delta S=12.9 \pm 0.1 \mathrm{kcal} / \mathrm{mol} ;$ and $\Delta G_{I T C}=-9.04 \pm 0.03 \mathrm{kcal} / \mathrm{mol}$ (Table 1).

\section{Magnesium dependence of the I/ $\mathrm{V}$ kissing-loop interaction}

Since $\mathrm{Mg}^{2+}$ ions are essential for formation of the I/V kissing-loop interaction, ITC experiments were performed at $25^{\circ} \mathrm{C}$ under varying concentrations of $\mathrm{MgCl}_{2}$ to examine the $\mathrm{Mg}^{2+}$ ion dependence of this interaction and determine conditions at which the $\mathrm{Mg}^{2+}$ ion concentration is saturated. A plot of the dissociation constants $\left(K_{D}\right)$ against the $\mathrm{MgCl}_{2}$ concentration indicates that the affinity of SLV for the SLIps substrate increases (decrease of $K_{D}$ ) with increasing $\mathrm{Mg}^{2+}$ ion concentration and reaches a plateau around 20 $\mathrm{mM} \mathrm{MgCl}$ (Fig. 4). Thus, subsequent ITC experiments were carried out in a buffer containing $20 \mathrm{mM} \mathrm{MgCl}$. 

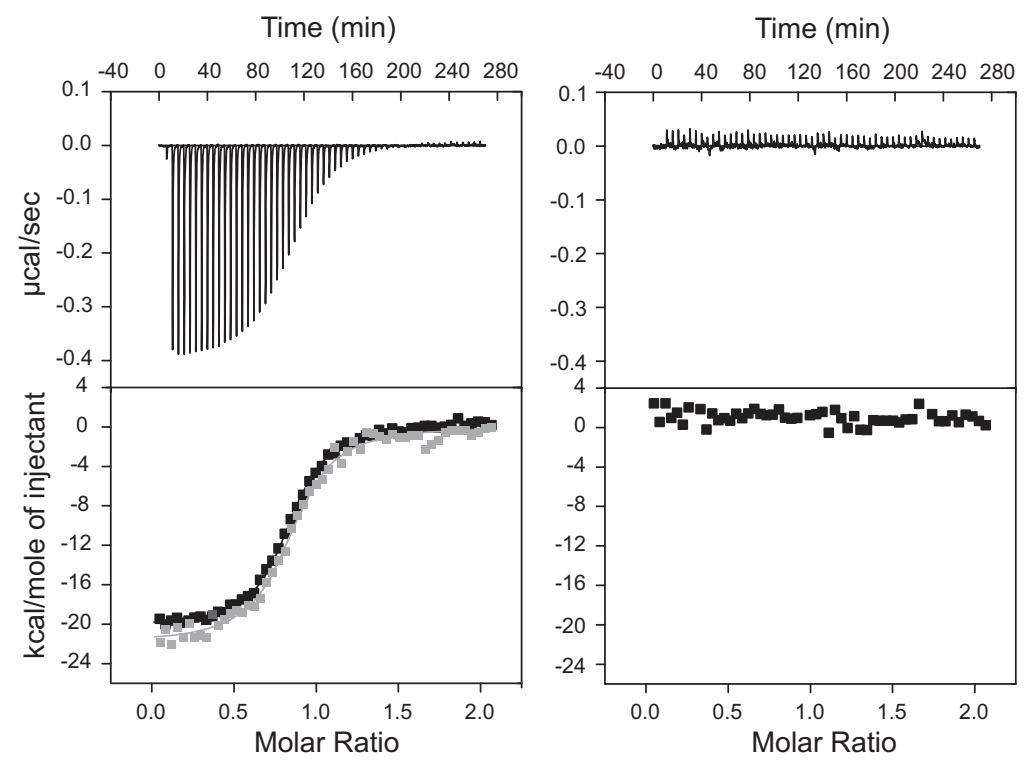

FIGURE 3. ITC data analysis of wild-type SLV binding to SLIps at $20 \mathrm{mM} \mathrm{MgCl}_{2}$. The raw data of a representative titration experiment are shown on the left top panel and the corresponding control experiment (only buffer in the cell) is shown on the right top panel. The isothermal curves, which represent the integrated data of the above titration experiments, are shown on the bottom panels. On the left bottom panel, two isothermal curves of the titration experiment are shown, before (black) and after (gray) subtraction of the control experiment. They both yield the same $K_{D}$ value $(0.24 \mu \mathrm{M})$. In the titration experiment, $100 \mu \mathrm{M}$ of wild-type SLV was used in the syringe and $10 \mu \mathrm{M}$ of SLIps was used in the cell.

The $\mathrm{Mg}^{2+}$ dependence of SLIps/SLV binding can also be analyzed as

$$
\left(\frac{\partial \ln \left(K_{A}\right)}{\partial \ln \left[\mathrm{Mg}^{2+}\right]}\right)=\Delta \Gamma_{2+},
$$

where $\Delta \Gamma_{2+}$ is the apparent interaction coefficient that represents the net uptake or release of divalent cations associated with the interaction (Draper 2008; Leipply et al. 2009). Although the plot of $\ln \left(K_{A}\right)$ versus $\ln \left[\mathrm{Mg}^{2+}\right]$ is generally linear within a certain range of $\mathrm{Mg}^{2+}$ concentration, it is not expected over the full range of $\mathrm{Mg}^{2+}$ concentration (Weixlbaumer et al. 2004; Draper 2008; Leipply et al. 2009), as observed here for the SLIps/SLV complex (Fig. 4B). Thus, our data are best fit by a second-order polynomial equation:

$$
\begin{aligned}
\ln \left(K_{A}\right)= & -0.1651\left(\ln \left[\mathrm{MgCl}_{2}\right]\right)^{2} \\
& -0.8162 \ln \left[\mathrm{MgCl}_{2}\right]+14.748 .
\end{aligned}
$$

The slope of this plot evaluated at the midpoint of the curve $\left(\left[\mathrm{MgCl}_{2}\right]=4.5 \mathrm{mM}\right)$ was used to estimate an apparent $\Delta \Gamma_{2+}$ value of 0.97 (Leipply et al. 2009). Maximum and minimum values of 1.46 and 0.71 , respectively, for $\Delta \Gamma_{2+}$ were derived by linear regression analysis using either the first four points or the last four points of the $\ln \left(K_{A}\right)$ versus $\ln \left[\mathrm{MgCl}_{2}\right]$ plot (Fig. $4 \mathrm{~B})$. The derived $\Delta \Gamma_{2+}$ values are termed "apparent" $\Delta \Gamma_{2+}$ because the experimental conditions, particularly the use of Tris buffer and the absence of monovalent salts, were selected to be compatible with those used for NMR structural characterization (Campbell et al. 2006; Bouchard et al. 2008; Bouchard and Legault 2014) but do not allow determination of accurate $\Delta \Gamma_{2+}$ values (Leipply et al. 2009). Nevertheless, this analysis indicates that there is an approximate net uptake of one $\mathrm{Mg}^{2+}$ ion associated with formation of the SLI/SLV complex in the concentration range between $0.5 \mathrm{mM}$ and $40 \mathrm{mM} \mathrm{MgCl}_{2}$.

\section{Effect of SLV sequence variations on the stability of the SLI/SLV complex}

As part of a previous study, VS ribozyme variants were kinetically characterized to evaluate the contribution of U700 and other SLV loop residues to SLI recognition (Bouchard et al. 2008). This study revealed that replacing U700 by A, C, or $\mathrm{G}$ does not significantly affect the ribozyme cleavage activity, whereas U700 deletion dramatically impairs this activity (Bouchard et al. 2008). In order to address the role of

\begin{tabular}{|c|c|c|c|c|c|c|}
\hline \multicolumn{7}{|l|}{ RNAs } \\
\hline Cell & Syringe & $K_{D}(\mu \mathrm{M})$ & $n$ & $\Delta H(\mathrm{kcal} / \mathrm{mol})$ & $-T \Delta S(\mathrm{kcal} / \mathrm{mol})$ & $\Delta G_{/ T C}{ }^{\mathrm{a}}(\mathrm{kcal} / \mathrm{mol})$ \\
\hline SLIps & WT SLV & $0.24 \pm 0.01$ & $0.84 \pm 0.01$ & $-22.0 \pm 0.1$ & $12.9 \pm 0.1$ & $-9.04 \pm 0.03$ \\
\hline SLIps & U700C SLV & $0.81 \pm 0.04$ & $0.83 \pm 0.01$ & $-21.5 \pm 1.0$ & $13.2 \pm 1.0$ & $-8.31 \pm 0.03$ \\
\hline SLIps & U695G SLV & $0.29 \pm 0.04$ & $1.0 \pm 0.1$ & $-27.0 \pm 0.5$ & $18.0 \pm 0.4$ & $-8.93 \pm 0.08$ \\
\hline SLIps & $\Delta U 700$ SLV & $50 \pm 5$ & $0.8 \pm 0.1$ & $-20.1 \pm 0.09$ & $14.19 \pm 0.03$ & $-5.87 \pm 0.06$ \\
\hline SLIps & C699G SLV & $>200$ & 1 & - & - & $>-5.05$ \\
\hline
\end{tabular}
U700 in SLI substrate recognition, we investigated the effect

TABLE 1. ITC data for binding of SLV variants to a preshifted SLI substrate (SLIps)

${ }^{\mathrm{a}} \Delta G_{I T C}=-R T \ln \left(K_{A}\right)$ at $T=298.15 \mathrm{~K}$.

${ }^{b}$ Given a low $c$ value $(c<1), n$ was fixed to 1 ; in this case, the $\Delta H$ and $-T \Delta S$ cannot be accurately determined (Turnbull and Daranas 2003). 

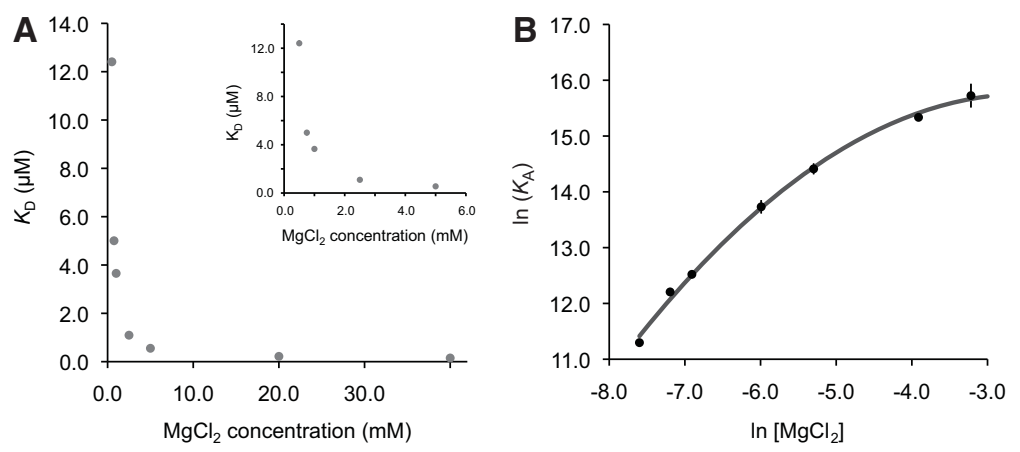

FIGURE 4. Magnesium ion dependence of the I/V kissing-loop interaction. (A) Dissociation constant $\left(K_{D}\right)$ for the SLIps/SLV complex with respect to $\mathrm{MgCl}_{2}$ concentration. The inset shows the same data on a different scale. $(B)$ Dependence of $\ln \left(K_{A}\right)$ on $\ln \left[\mathrm{MgCl}_{2}\right]$ for the SLIps/SLV complex. These data are best fit by a second-order polynomial equation: $y=0.1651 x^{2}-$ $0.8162 x+14.748$. In $A$ and $B$, error bars were calculated for each point from the standard deviations of two experiments, and are, in some cases, smaller than the data points.

of U700 deletion and other SLV sequence modifications on the thermodynamic stability of the SLI/SLV complex. ITC experiments were performed at $25^{\circ} \mathrm{C}$ in a buffer containing $20 \mathrm{mM} \mathrm{MgCl}_{2}$ with SLIps and different SLV variants (Fig. $2 \mathrm{~B})$. It was previously verified by native gel electrophoresis and NMR spectroscopy that under these conditions, these SLV variants adopt a stable hairpin conformation (Bouchard et al. 2008). As expected, all SLV variants bound to the SLIps substrate with an approximate stoichiometry $(n)$ of 1 (Table 1), except for the C699G variant for which no binding could be detected under our ITC conditions.

Changing the U700 base to a C (U700C) or changing the U-A closing base pair to a G-A (U695G) yields $K_{D}$ values of $0.81 \mu \mathrm{M}$ and $0.29 \mu \mathrm{M}$, respectively, which are on the same order of magnitude as that obtained with the wildtype SLV $\left(K_{D}=0.24 \mu \mathrm{M}\right)$ (Table 1$)$. In contrast, an SLV variant containing a U700 deletion ( $\triangle \mathrm{U} 700)$ displays a substantial decrease in affinity for SLIps with a $K_{D}$ value of $50 \mu \mathrm{M}$ (Table 1). For the C699G variant, thermodynamic parameters could not be derived even at high concentrations of RNA ( $1 \mathrm{mM}$ C699G SLV in the syringe and $100 \mu \mathrm{M}$ of SLIps in the cell), and a $K_{D}>200 \mu \mathrm{M}$ was estimated, assuming that the poor quality of the titration curve reflects a situation in which $c<1[c=$ (concentration of RNA in the cell)/ $K_{D}$ ] (Wiseman et al. 1989; Turnbull and Daranas 2003). Accordingly, this SLV variant was not expected to stably bind to the SLIps substrate, since the C699G variation disrupts one of the three $\mathrm{W}-\mathrm{C}$ base pairs at the kissing-loop junction (Rastogi et al. 1996; Bouchard and Legault 2014).

To compare the effect of SLV sequence variations on SLI binding with their effect on SLI cleavage by the VS ribozyme, we tabulated the relative $K_{A}$ values $\left[\left(K_{A}\right)_{\mathrm{WT}} /\left(K_{A}\right)_{\mathrm{VAR}}=\right.$ $\left.\left(K_{D}\right)_{\mathrm{VAR}} /\left(K_{D}\right)_{\mathrm{WT}}\right]$ obtained in the present study with the relative $k_{\text {cat }} / K_{M}$ values $\left[\left(k_{c a t} / K_{M}\right)_{\mathrm{WT}} /\left(k_{\text {cat }} / K_{M}\right)_{\mathrm{VAR}}\right]$ obtained previously (Table 2; Bouchard et al. 2008). In addition, the contributions of modified residues to the free energy of the I/V kissing-loop interaction were derived from the rela- tive $K_{A}$ values $\left\{\Delta \Delta G_{I T C}=R T \ln \left[\left(K_{A}\right)_{\mathrm{WT}}\right\}\right.$ $\left.\left.\left(K_{A}\right)_{\text {VAR }}\right]\right\}$ (Table 2 ). For the U700C and U695G variants, the $\left(K_{A}\right)_{\mathrm{WT}} /$ $\left(K_{A}\right)_{\mathrm{VAR}}$ ratios (3.4 and 1.2 , respectively) are similar to the $\left(k_{\text {cat }} / K_{M}\right)_{\mathrm{WT}} /\left(k_{\text {cat }} /\right.$ $\left.K_{M}\right)_{\text {VAR }}$ ratios (3.7 and 2.7, respectively). In both cases, the small ratios $(<4)$ indicate that neither the affinity of the $\mathrm{I} / \mathrm{V}$ kissing-loop interaction nor ribozyme activity is significantly affected by these modifications. In addition, the $\Delta \Delta G_{I T C}$ $(\leq 0.7 \mathrm{kcal} / \mathrm{mol})$ indicates that no substantial loss of free energy of binding resulted from these SLV modifications (Table 2). For the $\Delta \mathrm{U} 700$ variant, the large decrease in ribozyme activity corresponds to a $\left(k_{\text {cat }} / K_{M}\right)_{\mathrm{WT}} /\left(k_{\text {cat }} / K_{M}\right)_{\mathrm{VAR}}$ ratio of 140 , which is on the same order of magnitude as the respective $\left(K_{A}\right)_{\mathrm{WT}} /\left(K_{A}\right)_{\mathrm{VAR}}$ ratio of 210 (Table 2). The $\Delta \Delta G_{I T C}$ value of this variant $(3.2 \mathrm{kcal} / \mathrm{mol})$ indicates that the deletion of U700 results in an energetic cost of $\sim 3 \mathrm{kcal} / \mathrm{mol}$ for SLI binding (Table 2).

\section{Effect of SLI sequence variations on the stability of the SLI/SLV complex}

In the VS ribozyme, the kissing-loop interaction between SLI and SLV is accompanied by a structural rearrangement in SLI (Andersen and Collins 2000, 2001), in which SLI changes from an inactive (unshifted) to an active (shifted) conformation. The cytosines C635 to C637 (C15-17) (Fig. 1B) in helix Ib shift their position in the stem, excluding C634 (C14) (Fig. 1B) from the helix and rearranging the cleavage site internal loop (Andersen and Collins 2000). To better understand the importance of this helix shift in substrate recognition, we evaluated its energetic contribution by ITC using six different SLI variants (Fig. 2A). We selected shiftable variants that

TABLE 2. Comparison of thermodynamic and kinetic data associated with the I/N kissing-loop interaction in the VS ribozyme

\begin{tabular}{|c|c|c|c|}
\hline \multirow[b]{2}{*}{ Variant RNAs } & \multicolumn{2}{|c|}{ Thermodynamic data } & \multirow{2}{*}{ 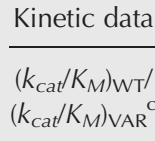 } \\
\hline & $\begin{array}{l}\left(K_{A}\right)_{\mathrm{WT}}^{\prime} \\
\left(K_{A}\right)_{\text {VAR }}{ }^{a}\end{array}$ & $\Delta \Delta G_{I T C}{ }^{\mathrm{b}}(\mathrm{kcal} / \mathrm{mol})$ & \\
\hline WT SLV & 1.0 & 0 & 1.0 \\
\hline U700C SLV & 3.4 & 0.73 & 3.7 \\
\hline U695G SLV & 1.2 & 0.10 & 2.7 \\
\hline$\Delta U 700$ SLV & $2.1 \times 10^{2}$ & 3.2 & $1.4 \times 10^{2}$ \\
\hline C699G SLV & $\geq 8.4 \times 10^{2}$ & $>4.0$ & $2.7 \times 10^{2}$ \\
\hline
\end{tabular}

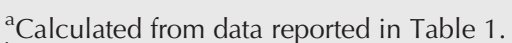

${ }^{\mathrm{b}} \Delta \Delta \mathrm{G}_{I T C}=R T \ln \left[\left(K_{A}\right)_{\mathrm{WT}} /\left(K_{A}\right)_{\mathrm{VAR}}\right]$ at $T=298.15 \mathrm{~K} ; \Delta \Delta G_{I T C}$ was used to compare the change in binding energy between various RNAs; these values reflect the difference in free energy observed as a result of each sequence variation.

${ }^{\mathrm{c}}$ Data taken from Bouchard et al. (2008). 
convert from an inactive to an active conformation upon SLV binding in the presence of $\mathrm{Mg}^{2+}$ ions (SLIsb and SLIsb $\Delta \mathrm{Ia}$ ) (Fig. 2A). We also selected preshifted variants that adopt a single active shifted conformation in their free form (SLIps and SLIps $\Delta$ Ia) (Fig. 2A). Similar shiftable and preshifted variants that lack stem $\mathrm{Ia}(\Delta \mathrm{Ia})$ were also investigated to evaluate the energetic cost of stem Ia in the formation of the SLI/SLV complex, since it was previously shown that removal of stem Ia increases ribozyme cleavage activity (Beattie and Collins 1997; Rastogi and Collins 1998; Zamel et al. 2004; Poon et al. 2006). Finally, we also investigated SLI variants containing a noncleavable double-stranded stem (SLIds1 and SLIds2) (Fig. 2A). The secondary structure of these six SLI variants in their free form was confirmed by native gel electrophoresis and NMR spectroscopy (Bouchard and Legault 2014). NMR spectroscopy was also used to demonstrate formation of stable kissing-loop complexes between several SLI variants and SLV (SLIsb $\Delta \mathrm{Ia} / \mathrm{SLV}$, SLIps/SLV, SLIps $\Delta \mathrm{Ia} /$ SLV, SLIds1/SLV, and SLIds2/SLV) (Bouchard and Legault 2014), which include the three proposed W-C base pairs. Moreover, these studies provide direct evidence that shiftable SLI variants, but not the preshifted or double-stranded variants, undergo the proposed helix shift upon SLV binding (Bouchard and Legault 2014).

The ITC results reveal higher affinities (lower $K_{D}$ ) of SLV for preshifted SLI variants compared to shiftable SLI variants (SLIps versus SLIsb and SLIps $\Delta$ Ia versus SLIsb $\Delta I a$ ) (Table 3 ). Among the shiftable SLI variants, a lower affinity for SLV is observed in the presence of stem Ia (SLIsb) than in its absence (SLIsb $\Delta \mathrm{Ia}$ ) (Table 3). In contrast, the presence of stem Ia does not significantly decrease the affinity of SLV to a preshifted SLI variant (SLIps versus SLIps $\Delta$ Ia) (Table 3). Not surprisingly, SLI variants containing a double-stranded stem bind SLV with affinities that closely match those of the preshifted SLI variants (SLIds1 and SLIds2 versus SLIps and SLIps $\Delta \mathrm{Ia}$ ) (Table 3). In terms of free energy (Table 3), these results show that SLV forms more stable complexes with preshifted SLI variants than with shiftable SLI variants. An energetic cost of $1.8 \mathrm{kcal} / \mathrm{mol}$ is associated with complex formation of shiftable versus preshifted SLI variants in the absence of stem Ia, and this can be directly attributed to the structural rearrangement of the shiftable substrate upon complex formation. The presence of stem Ia further reduces by $1 \mathrm{kcal} / \mathrm{mol}$ the thermodynamic stability of the SLI/SLV complex formed with a shiftable substrate but has essentially no effect on the stability of complexes formed with preshifted substrates. These results also indicate that the stability of SLI/ SLV complexes formed with several nonshiftable SLI variants (SLIps, SLIps $\triangle \mathrm{Ia}$, SLIds1, SLIds2) is influenced neither by the sequence nor the structure of the helical domain adjoining the terminal loop.

\section{The VS ribozyme I/V kissing-loop interaction is more stable than predicted}

In this study, we obtained $K_{D}$ values ranging from 0.24 to $0.71 \mu \mathrm{M}$ for binding of nonshiftable SLI variants to SLV (Tables 1, 3), indicating that small variations in experimental conditions (e.g., switching the titrant, addition of $50 \mathrm{mM}$ $\mathrm{NaCl}$ ) do not significantly affect the measured $K_{D}$ value (less than threefold). The observed $K_{D}$ values reflect the thermodynamic stability of the I/V kissing-loop interaction, which appears to be remarkably high given that only three $\mathrm{W}$-C base pairs are formed at the kissing-loop junction (Rastogi et al. 1996; Bouchard and Legault 2014). We compared the free energy values estimated at $37^{\circ} \mathrm{C}$ obtained for formation of SLI/SLV complexes with these nonshiftable SLI variants $\left(\Delta G_{I T C}\right.$ of -7.7 to $-8.5 \mathrm{kcal} / \mathrm{mol}$ ) (Table 4$)$ to the predicted $\Delta G$ value for formation of a comparable RNA duplex at $37^{\circ} \mathrm{C}$ according to nearest-neighbor calculations (Xia et al. 1998; Lorenz et al. 2006). The SLI/SLV kissingloop complex was investigated under high-salt conditions $\left(20 \mathrm{mM} \mathrm{MgCl}_{2}\right.$ ) that are comparable to those used for establishing nearest-neighbor calculations. The three proposed $\mathrm{W}-\mathrm{C}$ base pairs at the I/V kissing-loop junction form a short A-form helix, as shown in the NMR structure (Bouchard and Legault 2014). According to the nearest-neighbor thermodynamic calculation (Xia et al. 1998), the predicted $\Delta G\left(\Delta G_{p r e}\right)$ for the short RNA duplex

\section{$\frac{\mathrm{GUC}}{\mathrm{CAG}}$}

TABLE 3. ITC data for binding of SLI variants to SLV

\begin{tabular}{|c|c|c|c|c|c|c|}
\hline \multicolumn{2}{|c|}{ RNAs } & \multirow[b]{2}{*}{$K_{D}(\mu \mathrm{M})$} & \multirow[b]{2}{*}{$n$} & \multirow[b]{2}{*}{$\Delta H(\mathrm{kcal} / \mathrm{mol})$} & \multirow[b]{2}{*}{$-T \Delta S(\mathrm{kcal} / \mathrm{mol})$} & \multirow[b]{2}{*}{$\Delta G_{/ T C}{ }^{\mathrm{a}}(\mathrm{kcal} / \mathrm{mol})$} \\
\hline Cell & Syringe & & & & & \\
\hline SLV & SLIps & $0.71 \pm 0.04$ & $0.84 \pm 0.01$ & $-24.9 \pm 1.4$ & $16.5 \pm 1.4$ & $-8.39 \pm 0.04$ \\
\hline SLV & SLIsb $^{b}$ & $65 \pm 4$ & 1 & - & - & $-5.71 \pm 0.03$ \\
\hline SLV & SLIps $\Delta \mathrm{la}$ & $0.63 \pm 0.02$ & $1.13 \pm 0.02$ & $-24.2 \pm 0.7$ & $15.8 \pm 0.7$ & $-8.46 \pm 0.02$ \\
\hline SLV & SLIsb $\Delta \mathrm{la}$ & $12.5 \pm 1.1$ & $1.09 \pm 0.08$ & $-21.4 \pm 2.7$ & $14.7 \pm 2.7$ & $-6.69 \pm 0.05$ \\
\hline SLV & SLIds1 & $0.66 \pm 0.04$ & $1.03 \pm 0.02$ & $-25.2 \pm 0.6$ & $16.8 \pm 0.5$ & $-8.43 \pm 0.03$ \\
\hline SLV & SLIds2 & $0.41 \pm 0.04$ & $1.07 \pm 0.01$ & $-27.8 \pm 0.8$ & $19.1 \pm 0.7$ & $-8.71 \pm 0.06$ \\
\hline
\end{tabular}


TABLE 4. Comparison between predicted $\Delta G$ and experimental $\Delta G$ values (in $\mathrm{kcal} / \mathrm{mol}$ ) for several kissing-loop complexes

\begin{tabular}{|c|c|c|c|c|c|c|c|}
\hline \multirow[b]{2}{*}{ Kissing-loop complex } & \multirow[b]{2}{*}{ Sequence context } & \multirow[b]{2}{*}{$\Delta G_{\exp }$} & \multirow[b]{2}{*}{ Experimental conditions } & \multicolumn{2}{|c|}{$\begin{array}{l}\text { No } 5^{\prime} / 3^{\prime} \text { stacking } \\
\text { interactions }^{\mathrm{a}}\end{array}$} & \multicolumn{2}{|c|}{$\begin{array}{l}\text { With } 5^{\prime} / 3^{\prime} \text { stacking } \\
\text { interactions }\end{array}$} \\
\hline & & & & $\Delta G_{\text {pre }}$ & $\Delta G_{p r e}-\Delta G_{\exp }$ & $\Delta G_{\text {pre }}$ & $\Delta G_{p r e}-\Delta G_{\exp }$ \\
\hline $\begin{array}{l}\text { VS Ribozyme } \\
\text { I/ }\end{array}$ & $\frac{C G \cup C G}{A A G}$ & $\begin{array}{l}-8.5 \\
-7.9 \\
-7.8 \\
-7.8 \\
-7.7\end{array}$ & 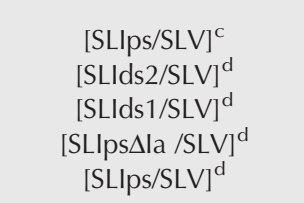 & -0.5 & $\begin{array}{l}8.0 \\
7.4 \\
7.3 \\
7.3 \\
7.2 \\
7\end{array}$ & -4.2 & $\begin{array}{l}4.3 \\
3.7 \\
3.6 \\
3.6 \\
3.5\end{array}$ \\
\hline $\begin{array}{l}\text { HIV-1 } \\
\text { TAR/TAR* }\end{array}$ & $\frac{C \cup G G G A G}{A A C C C U}$ & $\begin{array}{l}-9.8 \\
-9.3\end{array}$ & $\begin{array}{l}\mathrm{c} \\
\mathrm{e}\end{array}$ & -9.0 & $\begin{array}{l}0.8 \\
0.3\end{array}$ & -10.9 & $\begin{array}{l}-1.1 \\
-1.6\end{array}$ \\
\hline $\begin{array}{l}\text { ColE1 } \\
\text { RNAli/RNAlli }\end{array}$ & 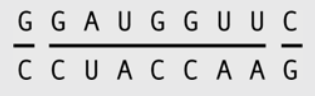 & -11.6 & $f$ & -7.9 & 3.7 & -13.5 & -1.9 \\
\hline $\begin{array}{r}\text { HIV-1 } \\
\text { DIS }\end{array}$ & $\frac{C \subset G A C C A}{G G C \cup G G}$ & -13.5 & g & -9.4 & 4.1 & -12.2 & 1.3 \\
\hline $\begin{array}{l}\text { MMLV } \\
\text { H3-18 }\end{array}$ & $A \frac{C G}{G C A}$ & $\begin{array}{l}-5.0 \\
-6.5\end{array}$ & $\begin{array}{l}\mathrm{c} \\
\mathrm{h}\end{array}$ & +2.2 & $\begin{array}{l}7.2 \\
8.7\end{array}$ & +1.2 & $\begin{array}{l}6.2 \\
7.7\end{array}$ \\
\hline
\end{tabular}

${ }^{a}$ The predicted $\Delta G$ values $\left(\Delta G_{p r e}\right)$ at $37^{\circ} \mathrm{C}$ were calculated based on nearest-neighbor calculations and do not include the effect of $5^{\prime}$ and $3^{\prime}$ stacking nucleotides (see text) (Serra and Turner 1995).

${ }^{\text {'The }} \Delta G_{\text {pre }}$ values were calculated based on nearest-neighbor calculations and include the effect of $5^{\prime}$ and $3^{\prime}$ stacking nucleotides (see text) (Serra and Turner 1995; Xia et al. 1998).

${ }^{\mathrm{C}}$ The $\Delta G_{\text {exp }}$ value for the VS Ribozyme SLIps/SLV complex was derived herein from ITC data collected at $25^{\circ} \mathrm{C}$ in $10 \mathrm{mM} \mathrm{Tris} \mathrm{pH} 7.0$ and 20 $\mathrm{mM} \mathrm{MgCl} 2$ (Table 1). The same conditions were also used herein for the HIV-1 TAR/TAR* $\left(K_{D}=5.89 \pm 0.48 \mathrm{nM}, \Delta H=-47.73 \mathrm{kcal} / \mathrm{mol}\right.$ at $298.15 \mathrm{~K})$ and the MMLV H3-18 $\left(K_{D}=0.134 \pm 0.009 \mathrm{mM}, \Delta H=-12.62 \mathrm{kcal} / \mathrm{mol}\right.$ at $\left.298.15 \mathrm{~K}\right)$ complexes. The $K_{A}$ values at $37^{\circ} \mathrm{C}$ were first derived using the Van't Hoff equation. The $\Delta G_{\exp }$ values were then derived at $37^{\circ} \mathrm{C}$ using $\Delta G_{\text {exp }}=-R T \ln \left(K_{A}\right)$.

${ }^{\mathrm{d}}$ The $\Delta G_{\text {exp }}$ value for these VS Ribozyme SLI/SLV complexes were estimated as in footnote c, above, at $37^{\circ} \mathrm{C}$ using thermodynamic values obtained herein from ITC data collected at $25^{\circ} \mathrm{C}$ in $10 \mathrm{mM}$ Tris pH 7.0, $50 \mathrm{mM} \mathrm{NaCl}$, and $20 \mathrm{mM} \mathrm{MgCl}$ (Table 3).

${ }^{\mathrm{e}}$ The $K_{\mathrm{A}}$ value at $37^{\circ} \mathrm{C}$ for the HIV-1 TAR/TAR* complex was estimated by using the Van't Hoff equation, a measured $K_{D}$ of $14.5 \mathrm{nM}$ obtained by SPR at $23^{\circ} \mathrm{C}$ in $20 \mathrm{mM}$ HEPES pH 7.3, $20 \mathrm{mM}$ sodium acetate, $140 \mathrm{mM}$ potassium acetate, and $10 \mathrm{mM}$ magnesium acetate (Ducongé et al. 2000), and a $\Delta H$ value of $-39.2 \mathrm{kcal} / \mathrm{mol}$ obtained by SPR in $20 \mathrm{mM}$ HEPES $\mathrm{pH} 7.3,20 \mathrm{mM}$ sodium acetate, $140 \mathrm{mM}$ potassium acetate, and $1 \mathrm{mM}$ magnesium acetate (Ducongé et al. 2000). The $\Delta G_{\exp }$ value was then calculated using $\Delta G_{\exp }=-R T \ln \left(K_{A}\right)$ at $T=310.15 \mathrm{~K}$.

${ }^{\mathrm{f}}$ The $K_{A}$ value at $37^{\circ} \mathrm{C}$ for the ColE1 RNAli-RNAlli was estimated by using a modified Van't Hoff equation $\left[K_{A}=\left(4 / C_{T}\right) \bullet \exp (-\Delta H / R \bullet(1 / T-1 /\right.$ $\left.T_{m}\right)$ )] (Marky and Breslauer 1987) and the following experimental values previously obtained from UV melting curve experiments (Gregorian and Crothers 1995): melting temperature $\left(T_{m}\right)$ of $40^{\circ} \mathrm{C}, \Delta H=-47.5 \mathrm{kcal} / \mathrm{mol}$ and a total strand concentration $\left(C_{T}\right)$ of $2 \mu \mathrm{M}$. The $\Delta G_{\text {exp }}$ value was then calculated using $\Delta G_{\exp }=-R T \ln \left(K_{A}\right)$ at $T=310.15 \mathrm{~K}$.

${ }^{\mathrm{g}}$ The $\Delta \mathrm{G}_{\text {exp }}$ value for the HIV-1 DIS complex is the standard free energy at $37^{\circ} \mathrm{C}$ derived from UV melting curves obtained in $10 \mathrm{mM}$ sodium cacodylate $\mathrm{pH}=6.8$ and $1 \mathrm{M} \mathrm{NaCl}$ (Weixlbaumer et al. 2004).

${ }^{\mathrm{h}}$ The $\Delta G_{\exp }$ value for the MMLV H3-18 complex is the standard free energy at $37^{\circ} \mathrm{C}$ derived from UV melting curves obtained in $10 \mathrm{mM}$ sodium phosphate $\mathrm{pH}=6.5$ and $50 \mathrm{mM} \mathrm{NaCl}$ (Kim and Tinoco 2000).

composed of the same sequence as the I/V kissing-loop interaction

$$
\frac{\mathrm{G}_{630} \mathrm{U}_{631} \mathrm{C}_{632}}{\mathrm{C}_{699} \mathrm{~A}_{698} \mathrm{G}_{697}}
$$

is $-0.5 \mathrm{kcal} / \mathrm{mol}$ under standard conditions (Table 4). The NMR structure of the SLIds2/SLV complex also reveals $5^{\prime}$ and $3^{\prime}$-stacking interactions, which are known to contribute to helix stability (Fig. 1C). They include a $5^{\prime}$-stacking interaction between C629 and G630 as well as 3'-stacking interactions between C632 and G633 in SLI and between C699 and A701 in SLV (Bouchard and Legault 2014). If we incorporate these stacking interactions to our thermodynamic calculations using nearest-neighbor interactions involving $3^{\prime}$ and $5^{\prime}$ unpaired nucleotides (Serra and Turner 1995), a $\Delta G_{\text {pre }}$ value of $-4.2 \mathrm{kcal} / \mathrm{mol}$ is obtained for the resulting

\section{CGUCG \\ $\mathrm{A} \overline{\mathrm{CAG}}$}

duplex (Table 4). Nonetheless, this $\Delta G_{p r e}$ value still differs by $3.5-4.3 \mathrm{kcal} / \mathrm{mol}$ from the range of $\Delta G_{I T C}$ values associated with formation of the I/V kissing-loop interaction. Thus, the I/V kissing-loop interaction is significantly more stable than a three-base-pair RNA duplex of the same sequence, even when stacking interactions with $5^{\prime}$ and $3^{\prime}$ nucleotides are included in the free energy calculation of the RNA duplex.

\section{Comparison with thermodynamic parameters of other kissing-loop interactions}

A few other known kissing-loop complexes have been thoroughly investigated both structurally and thermodynamically 


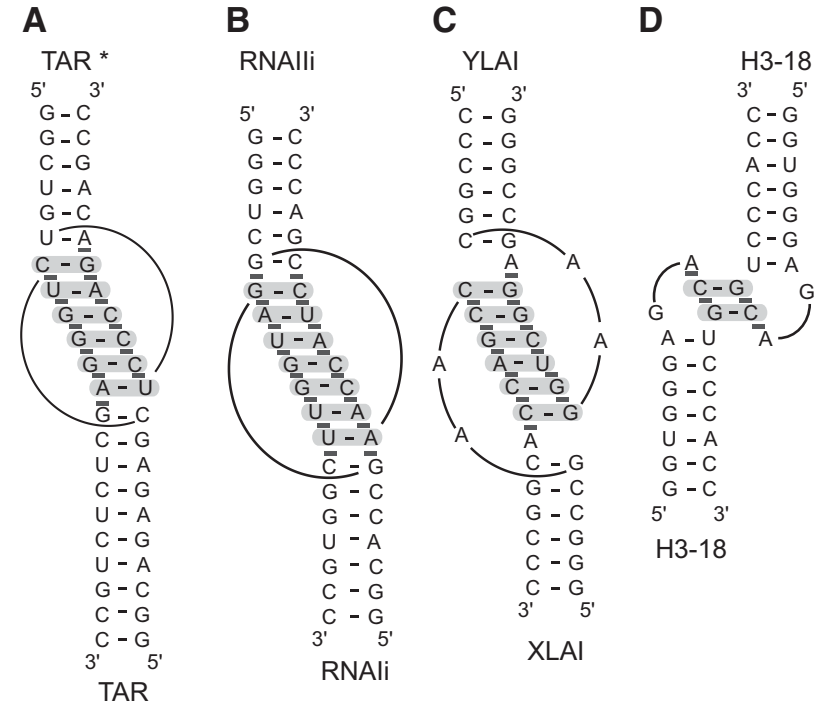

FIGURE 5. Primary and secondary structures of other kissing-loop interactions considered in this study. (A) The HIV-1 TAR/TAR* kissingloop complex used for the present study. Similar complexes were used in previous thermodynamic studies of the TAR/TAR* complex (Ducongé et al. 2000; Nair et al. 2000). (B) The ColE1 RNAIi/RNAIIi complex previously thermodynamically characterized by UV melting curves (Gregorian and Crothers 1995). (C) The HIV-1 DIS complex (XLAI/ YLAI) previously investigated by UV melting studies (Weixlbaumer et al. 2004). (D) The MMLV H3-18 kissing-loop complex used here and in previous UV melting studies (Kim and Tinoco 2000). In $A-D$, interactions at the kissing-loop junction are highlighted by pale gray shading for W-C base pair and dark gray boxes for base stacking, according to previously determined three-dimensional structures of the HIV-1 TAR/TAR* (pdb code 1KIS.pdb) (Chang and Tinoco 1997), ColE1 RNAIi/RNAIIi (pdb code 1BJ2) (Lee and Crothers 1998), HIV-1 DIS (pdb code 2B8R) (Ennifar et al. 2001), and MMLV H3-18 kissingloop complexes (pdb code 1F5U) (Kim and Tinoco 2000).

(Fig. 5), and we examined their stability by comparing their experimental $\Delta G$ values obtained from previous studies $\left(\Delta G_{\text {exp }}\right)$ with their $\Delta G$ value predicted according to nearestneighbor calculations $\left(\Delta G_{\text {pre }}\right)$. With the exception of the Moloney murine leukemia virus (MMLV) H3-18 complex, the kissing-loop complexes that we considered have been thermodynamically investigated under high-salt conditions, either at $1 \mathrm{M} \mathrm{NaCl}$ or high $\mathrm{Mg}^{2+}$ concentrations (5-10 mM $\mathrm{MgCl}_{2}$ ) (Table 4), that are comparable to those used for establishing nearest-neighbor calculations (Xia et al. 1998; Lorenz et al. 2006). The $\Delta G_{\text {pre }}$ values were calculated as for the SLI/SLV complex based on available high-resolution structures (Fig. 5). For the HIV-1 TAR/TAR*, ColE1 RNAIi/RNAIIi, and HIV-1 DIS complexes, the experimental $\Delta G$ values $\left(\Delta G_{\text {exp }}\right)$ and the $\Delta G_{\text {pre }}$ can differ considerably $(0.3-$ $4.1 \mathrm{kcal} / \mathrm{mol}$ ) when only base-pair stacking interactions are taken into account for calculation of the $\Delta G_{\text {pre }}$ value but generally differ less $(<2 \mathrm{kcal} / \mathrm{mol})$ when $5^{\prime} / 3^{\prime}$ stacking interactions are taken into account (Table 4 ). In contrast, for the MMLV H3-18 complex, which contains only two W-C base pairs at the kissing-loop junction (Fig. 5), $\Delta G_{p r e}-\Delta G_{\exp }=7.7$ $\mathrm{kcal} / \mathrm{mol}$ when $5^{\prime} / 3^{\prime}$ stacking interactions are taken into account (Table 4), indicating a more stable interaction than predicted by the thermodynamic model. In summary, except for MMLV H3-18 kissing-loop interaction and the VS ribozyme SLI/SLV interaction, the values of $\Delta G_{\exp }$ and $\Delta G_{\text {pre }}$ obtained for the other kissing-loop interactions investigated are similar.

In order to verify that our ITC conditions were not responsible for the unexpectedly large $\Delta G_{p r e}-\Delta G_{\text {exp }}$ value obtained for the I/V kissing-loop interaction, we performed control ITC experiments with the HIV-1 TAR/TAR* and MMLV H3-18 complexes (Fig. 5) under the same conditions as those used for the SLIps/SLV complex (Table 1). For the HIV-1 TAR/TAR* complex, we derived a $\Delta G_{I T C}$ of $-9.8 \mathrm{kcal} / \mathrm{mol}$ (Table 4 ), which is similar to the value of $\Delta G_{\exp }$ of $-9.3 \mathrm{kcal} /$ mol derived from a previous study (Table 4). For the MMLV H3-18 complexes, the use of our ITC conditions yielded a $\Delta G_{I T C}$ of $-5.0 \mathrm{kcal} / \mathrm{mol}$ (Table 4 ), which indicates a weaker interaction than previously established under lower salt conditions $\left(\Delta G_{\text {exp }}\right.$ of $\left.-6.5 \mathrm{kcal} / \mathrm{mol}\right)$ (Kim and Tinoco 2000$)$. However, with this new experimental $\Delta G_{\exp }$ value $\left(\Delta G_{I T C}\right)$, the difference with $\Delta G_{\text {pre }}$ is still fairly high $(6.2 \mathrm{kcal} / \mathrm{mol})$. Thus, both the MMLV H3-18 and I/V kissing-loop interactions are substantially more stable than predicted from thermodynamic calculations, and their remarkable stability is not due to exceptional experimental conditions.

\section{Thermodynamic characterization of SLI/ribozyme complexes}

To characterize the thermodynamic parameters for SLI substrate recognition in the context of the trans-cleaving VS ribozyme (VS Rz) (Fig. 1), we selected two SLI substrate variants (Fig. 2A) in which a 2'-O-methyl was introduced at nucleotide G-1 to prevent cleavage by the ribozyme, either a shiftable substrate with no stem Ia (SLIsb $\Delta \mathrm{Ia}-1 \mathrm{~m})$ or a preshifted substrate with stem Ia (SLIps-1m). ITC experiments were performed at $25^{\circ} \mathrm{C}$ and $20 \mathrm{mM} \mathrm{MgCl}_{2}$ using each of these noncleavable SLI analogs with either SLV or the VS $\mathrm{Rz}$ to extract the thermodynamic parameters associated with the resulting complexes (Table 5). The $K_{D}$ values associated with SLV binding to the noncleavable SLI analogs are within threefold of those obtained for SLV binding to the corresponding unmodified SLI variants (Tables 3, 4) (SLIsb $\Delta \mathrm{Ia}-1 \mathrm{~m} / \mathrm{SLV}$ versus SLIsb $\Delta \mathrm{Ia} / \mathrm{SLV}$ and SLIps-1m/SLV versus SLIps/SLV), indicating that the 2 '-O-methyl modification does not significantly affect the binding affinity. Such small changes in $K_{D}$ values could be simply due to differences in experimental conditions (the titrant is an SLI derivative for Table 3, but SLV for Table 4) as described above for the SLIps/SLV interaction. More importantly, the $K_{D}$ values for binding of the noncleavable SLI analogs to the VS Rz are within 1.5-fold of those obtained for binding of the same SLI analogs to the free SLV (Table 5) (SLIsb $\Delta \mathrm{Ia}-1 \mathrm{~m} /$ VS Rz versus SLIsb $\Delta \mathrm{Ia}-1 \mathrm{~m} / \mathrm{SLV}$ and SLIps- $1 \mathrm{~m} / \mathrm{VS} \mathrm{Rz}$ versus 
TABLE 5. ITC data for binding of noncleavable SLI substrates to SLV and VS Rz

\begin{tabular}{|c|c|c|c|c|c|c|}
\hline \multicolumn{7}{|l|}{ RNAs } \\
\hline Cell & Syringe & $K_{D}(\mu \mathrm{M})$ & $n$ & $\Delta H(\mathrm{kcal} / \mathrm{mol})$ & $-T \Delta S(\mathrm{kcal} / \mathrm{mol})$ & $\Delta G_{/ T C}{ }^{\mathrm{a}}(\mathrm{kcal} / \mathrm{mol})$ \\
\hline SLIps-1m & SLV & $0.21 \pm 0.01$ & $0.95 \pm 0.02$ & $-32.5 \pm 0.1$ & $23.4 \pm 0.1$ & $-9.11 \pm 0.04$ \\
\hline SLIsb $\Delta \mathrm{la}-1 \mathrm{~m}$ & SLV & $3.6 \pm 0.3$ & $0.86 \pm 0.01$ & $-32.9 \pm 1.1$ & $25.5 \pm 1.1$ & $-7.43 \pm 0.06$ \\
\hline SLIps-1m & VS Rz & $0.30 \pm 0.02$ & $1.07 \pm 0.05$ & $-28.0 \pm 0.6$ & $19.2 \pm 0.6$ & $-8.90 \pm 0.03$ \\
\hline SLIsb $\Delta \mathrm{Ia}-1 \mathrm{~m}$ & VS Rz & $4.56 \pm 0.01$ & $0.82 \pm 0.04$ & $-42.6 \pm 1.6$ & $35.3 \pm 1.6$ & $-7.286 \pm 0.001$ \\
\hline
\end{tabular}

SLIps-1m/SLV). These results indicate that binding of these SLI variants to either SLV or VS Rz involves similar free energies. Although the $2^{\prime}$-O-methyl modification used for our studies prevents interaction(s) with the $2^{\prime}-\mathrm{OH}$ at the cleavage site, SLI docking interactions with the VS ribozyme does not contribute significantly to the ground state of the SLI/ribozyme complexes tested here. As a result, the I/V kissingloop interaction is the key determinant of SLI substrate recognition in the VS ribozyme.

\section{DISCUSSION}

\section{The I/V kissing-loop interaction is remarkably stable}

In the present study, ITC experiments were performed to determine the thermodynamic parameters associated with the I/V kissing-loop interaction of the VS ribozyme. Interestingly, the ITC data revealed that formation of the SLI/SLV complex with several SLI variants is remarkably high, more stable by $7-8 \mathrm{kcal} / \mathrm{mol}$ than predicted for a comparable RNA duplex with three Watson-Crick base pairs. As discussed below, this is likely due to extensive stacking at the kissing-loop junction ( $\geq 4 \mathrm{kcal} / \mathrm{mol}$ ), the stabilizing effect of $\mathrm{Mg}^{2+}$ ions, the U-turn loop structures of SLI and SLV, and the ribose-phosphate of the extruded U700 in SLV.

The high stability of the SLI/SLV complex with three W-C base pairs at the kissing-loop junction cannot be predicted from thermodynamic calculations even when both basepair stacking and $5^{\prime} / 3^{\prime}$ stacking interactions are considered in estimating $\Delta G_{\text {pre }}\left(\Delta G_{p r e}-\Delta G_{\exp }=\sim 4 \mathrm{kcal} / \mathrm{mol}\right)$, and this is not a result of exceptional experimental conditions. For other kissing-loop interactions, namely the HIV-1 TAR/ TAR*, the ColE1 RNAIi/RNAIIi, and the HIV-1 DIS complexes, the $\Delta G_{\text {exp }}$ and $\Delta G_{\text {pre }}$ values differ by $<2 \mathrm{kcal} / \mathrm{mol}$ when both base-pair stacking and $5^{\prime} / 3^{\prime}$ stacking interactions are considered in estimating $\Delta G_{\text {pre }}$. Thus, the rules governing RNA duplex stability can be useful for estimating the stability of these kissing-loop complexes containing 6-7 W-C base pairs when both base-pair stacking and $5^{\prime} / 3^{\prime}$ stacking interactions are taken into account. In contrast, similar thermodynamic calculations were not successful in predicting the high stability of the MMLV H3-18 complex $\left(\Delta G_{p r e}-\Delta G_{\exp }\right.$ $=7-8 \mathrm{kcal} / \mathrm{mol}$ ), which contains only two $\mathrm{W}-\mathrm{C}$ base pairs at the kissing-loop junction (Kim and Tinoco 2000; Li et al. 2006; Chen and Garcia 2012). Thus, it appears that kissing-loop complexes with 2-3 Watson-Crick base pairs are generally more stable than predicted. Clearly, other factors than those computed by the thermodynamic model must contribute to the high stability of both the MMLV H3-18 complex and the VS ribozyme I/V kissing-loop complex.

\section{Extensive stacking at the I/V junction}

The compact network of hydrogen-bonding and stacking interactions observed at the kissing-loop junction in the NMR structure of the SLIds2/SLV complex (Bouchard and Legault 2014) may not be justly accounted for by the thermodynamic model. In this structure, the kissing-loop junction contains the three predicted $\mathrm{W}-\mathrm{C}$ base pairs forming a short helix and also two base triples, one at each end of the short helix. For the two base triples, the thermodynamic model takes into account stacking interactions as if they were from unpaired nucleotides at the end of a helix but does not consider the base triples as a whole. Both base triples are part of an intricate structure that extends from the kissing-loop junction toward the stems of SLI and SLV to create a continuously stacked structure. This continuous stacking and several hydrogen bonds not computed by the thermodynamic model likely contribute to the remarkable stability of the SLI/SLV complex.

\section{Role of $\mathrm{Mg}^{2+}$ in the I/V kissing-loop interaction}

Our study confirms that $\mathrm{Mg}^{2+}$ is required for formation of a stable I/V kissing-loop interaction, as previously inferred from chemical probing data (Rastogi et al. 1996; Rastogi and Collins 1998; Sood et al. 1998; Hiley and Collins 2001). The $K_{D}$ of the SLIps/SLV interaction could not be measured by ITC at $\mathrm{MgCl}_{2}$ concentrations below $0.5 \mathrm{mM}$ because of the lower affinity of the complex at lower $\mathrm{MgCl}_{2}$ concentrations. Starting at $0.5 \mathrm{mM} \mathrm{MgCl}$, we observed a decrease in $K_{D}$ with increasing $\mathrm{Mg}^{2+}$ ion concentration to reach a plateau around $20 \mathrm{mM} \mathrm{MgCl}_{2}$. In the interval between $0.5 \mathrm{mM}$ and $40 \mathrm{mM} \mathrm{MgCl}_{2}$, a net uptake of $\sim 1 \mathrm{Mg}^{2+}$ ion is associated with formation of the SLI/SLV complex.

It was previously estimated from the variation of $T_{m}$ values with $\mathrm{Mg}^{2+}$ concentration that formation of kissing-loop 
complexes derived from the HIV-1 TAR-TAR*, the HIV-1 DIS, and the ColE1 RNAI-RNAII interactions also involves net uptakes of 1-2 $\mathrm{Mg}^{2+}$ (Gregorian and Crothers 1995; Ducongé et al. 2000; Weixlbaumer et al. 2004). Such $\mathrm{Mg}^{2+}$ uptakes are likely necessary to neutralize the high charge density created by phosphate clusters at the loop-loop junction of these complexes (Chang and Tinoco 1997; Lee and Crothers 1998; Ennifar et al. 2001; Draper 2008; Lebars et al. 2008; Van Melckebeke et al. 2008). In the I/V kissingloop complex, $\mathrm{Mg}^{2+}$ ions likely play a similar role, since several phosphate clusters are found at the kissing-loop junction (Bouchard and Legault 2014). From detailed NMR structural characterization of the free SLI and SLV loops (Flinders and Dieckmann 2001; Campbell and Legault 2005; Campbell et al. 2006) as well as the SLI/SLV complex (Bouchard and Legault 2014), we know that formation of the SLI/SLV complex leads to a more ordered and compact SLI loop, but creates only minor changes in the SLV loop structure (Bouchard and Legault 2014). Thus, there is a net increase in electronegative charge density upon complex formation that is due to both SLI folding into a more compact loop structure and formation of intermolecular interactions at the kissing-loop junction (Bouchard and Legault 2014). Our current structural understanding of $\mathrm{Mg}^{2+}$ interactions associated with formation of the I/V kissing-loop complex is limited to the free forms of each stem-loop; whereas $\mathrm{Mg}^{2+}$ do not grossly affect the disordered loop I (Flinders and Dieckmann 2001), it induces a conformation change in the SLV loop, stabilizing a canonical U-turn fold with four specific $\mathrm{Mg}^{2+}$ binding sites (Campbell and Legault 2005; Campbell et al. 2006). Three of these four preferential sites identified by NMR in the free SLV loop interact with phosphate groups in the major groove and likely play a similar role in the SLI/SLV complex. Future studies aimed at localizing $\mathrm{Mg}^{2+}$ binding sites in the SLI/SLV complex should help better understand how specific $\mathrm{Mg}^{2+}$ binding sites at the kissing-loop junction contribute to the stability of the I/V interaction.

\section{Importance of $U$ turns in the I/ V kissing-loop interaction}

U-turn loop structures facilitate other RNA interactions, such as codon-anticodon interactions (Grosjean et al. 1976; Moras et al. 1986) and antisense RNA regulation (Franch et al. 1999; Franch and Gerdes 2000). It has been known for some time that trinucleotides bind more tightly to a complementary tRNA anticodon than would be expected for complementary RNA oligonucleotides (Grosjean et al. 1976). In pioneering binding experiments with a kissingloop complex formed between the complementary anticodons of yeast tRNA ${ }^{\text {Phe }}$ and Escherichia coli tRNA $^{\text {Glu }}$, a $K_{A}$ of $3.6 \times 10^{5} \mathrm{M}^{-1}$ and $\Delta H$ of $-25 \mathrm{kcal} / \mathrm{mol}$ were measured at $25^{\circ} \mathrm{C}$ and $10 \mathrm{mM} \mathrm{MgSO}_{4}\left(\Delta G_{\exp }\right.$ at $37^{\circ} \mathrm{C}$ of $-6.88 \mathrm{kcal} /$ $\mathrm{mol}$ ), which is more stable by $7.7 \mathrm{kcal} / \mathrm{mol}$ than predicted for the corresponding RNA duplex when only base-pair stacking interactions are taken into account $\left(\Delta G_{\text {pre }}\right.$ of +0.81 $\mathrm{kcal} / \mathrm{mol}$ ) (Grosjean et al. 1976). Interestingly, this $\Delta G_{p r e^{-}}$ $\Delta G_{\text {exp }}$ value is very similar to that of $7.2-8.0 \mathrm{kcal} / \mathrm{mol} \mathrm{ob-}$ tained for the SLI/SLV complexes (Table 4). In the same study, three potential sources of affinity enhancement were identified: (1) the "loop constraint" or closure of the anticodon sequences into hairpin loops; (2) the stabilizing effect of dangling ends; and (3) the extra stability provided by modified nucleotides that contribute to $3^{\prime}$ stacking. This "loop constraint" that was identified is likely due to the U-turn loop conformation that may promote intermolecular binding in several ways. In the SLI/SLV complex, it promotes stacking of the interacting bases in a near A-form geometry compatible with $\mathrm{W}-\mathrm{C}$ base-pairing. Such stacking is present in free SLV, but not in free SLI, and thus is increased upon formation of the SLI/SLV complex. In addition, the U turn conformation allows continuous stacking between bases of the kissing loop and adjoining stems in the SLI/SLV complex. Furthermore, the U-turn structure may promote kissingloop formation by retracting the phosphate backbone away from the interface, thereby reducing electrostatic repulsion. Binding of $\mathrm{Mg}^{2+}$ to the U-turn loop structure, as observed for the U-turn of SLV (Campbell et al. 2006) and anticodon loops (Westhof et al. 1988; Ogle et al. 2001), likely helps further reduce electrostatic repulsion at the loop-loop junction, thereby contributing to the remarkable stability of kissingloop interactions involving U-turn structures.

\section{Importance of U700 in the I/V kissing-loop interaction}

Although the role of loop $\mathrm{V}$ nucleotides involved in the $\mathrm{U}$ turn $\left(\mathrm{U}_{696} \mathrm{G}_{697} \mathrm{~A}_{698}\right)$ and the $\mathrm{I} / \mathrm{V}$ kissing-loop interaction $\left(\mathrm{G}_{697} \mathrm{~A}_{698} \mathrm{C}_{699}\right)$ are well understood, that of U700 has remained more elusive (Bouchard et al. 2008). NMR structural studies of SLV demonstrate that upon addition of $\mathrm{Mg}^{2+}$, the largest conformational change in loop V involves U700, which becomes completely extruded from the SLV loop fold (Campbell and Legault 2005; Campbell et al. 2006). In our previous enzymatic study of SLV loop variants (Bouchard et al. 2008), modification of U700 by a C, A, or G had negligible effects on ribozyme trans cleavage activity $\left(k_{c a t}\right)$ $K_{M}$ ), whereas deletion of U700 significantly reduced the $k_{\text {cat }} / K_{M}$. Similarly, ITC investigations of the I/V kissingloop interaction using isolated stem-loops demonstrate that a U700C modification does not significantly affect the affinity of the SLI/SLV interaction, whereas deletion of U700 significantly reduces the affinity of this interaction. Thus, the role of U700 is confined to the I/V kissing-loop interaction and likely not other aspects of the cleavage reaction.

Both thermodynamic and kinetic data indicate that it is the ribose phosphate of the extruded U700 residue and not its nucleobase that contributes to the stability of the I/V kissing-loop interaction. In agreement with these results, the U700 base is disordered in the structure of the SLI/SLV 
complex and does not appear to form any stable interactions with SLI (Bouchard and Legault 2014). Interestingly, a comparison between the thermodynamic parameters of the wildtype SLV and the $\Delta \mathrm{U} 700$ variant indicates that the free energy loss of $\sim 3 \mathrm{kcal} / \mathrm{mol}$ is due to both unfavorable entropic (1.3 $\mathrm{kcal} / \mathrm{mol}$ ) and enthalpic changes $(1.9 \mathrm{kcal} / \mathrm{mol})$ (Table 1$)$. As previously suggested, U700 could provide an entropic advantage for substrate recognition by increasing the loop dynamics and/or by serving as a spacer to increase the flexibility of the loop (Bouchard et al. 2008). Such loop dynamics may contribute the necessary plasticity within the SLV loop structure to optimize the intermolecular contacts upon formation of the kissing-loop interaction (Bouchard and Legault 2014). In addition, the ribose-phosphate backbone of U700 possibly contributes to the free enthalpy of the SLI/SLV complex through hydrogen bonding between one of the two nonbridging phosphate oxygens of U700 and an amino proton of A701, as these atoms are relatively close to another $(3.0 \pm 0.4 \AA$ in the 20 lowest-energy structures $)$ in the NMR structures (Fig. 1D; Bouchard and Legault 2014). This interaction with the phosphate of U700 likely stabilizes the $\mathrm{A} 14^{\mathrm{V}}-\mathrm{U} 8^{\mathrm{V}}-\mathrm{C} 10^{\mathrm{I}}$ base triple at the kissing-loop junction (Fig. 1D). The ribose-phosphate of U700 could also contribute to the enthalpic stability of the SLI/SLV complex through its interaction with a $\mathrm{Mg}^{2+}$ ion (Bouchard et al. 2008). This possibility is supported by our previous observations that the structure of the free SLV loop is stabilized by $\mathrm{Mg}^{2+}$ ions and that a $\mathrm{Mg}^{2+}$ ion directly coordinates the $5^{\prime}$-phosphate of U700 (Campbell et al. 2006). Although $\mathrm{Mg}^{2+}$ ion binding sites have not been mapped within the SLI/SLV complex, the SLV loop within this complex adopts a structure that resembles its free conformation in the presence of $\mathrm{Mg}^{2+}$ ions (Bouchard and Legault 2014). Taking into account these considerations, it is likely that the $\mathrm{Mg}^{2+}$-U700 5'-phosphate interaction somehow contributes to the stability of the complex. Thus, the ribose-phosphate of U700 likely contributes in several different ways to the remarkable stability of the I/V kissing-loop interaction.

\section{Preshifting of the SLI substrate enhances its affinity for SLV}

The SLI/SLV complex is highly stable when formed with preshifted substrates, but less so when formed with shiftable substrates. Using SLI substrates lacking stem Ia, we measured an increase of one order of magnitude in $K_{D}$ for the SLI/SLV complex when replacing a preshifted SLI (SLIps $\Delta \mathrm{Ia})$ by a comparable shiftable SLI (SLIsb $\Delta \mathrm{Ia}$ ), indicating that shifting the SLI helix in this context entails an energetic cost of 1.8 $\mathrm{kcal} / \mathrm{mol}$. These results are consistent with a previous study in which $K_{D}$ values were measured for several VS ribozyme/SLI complexes (Zamel and Collins 2002). Two such complexes were formed using so-called "opened-loop" SLI products that are similar to SLIps $\Delta \mathrm{Ia}$ and SLIsb $\Delta \mathrm{Ia}$ because they are devoid of stem Ia and contain a G627A mutation in the loop (equivalent to A7 in SLIps $\Delta \mathrm{Ia}$ and SLIsb $\Delta \mathrm{Ia}$ ) (Fig. 2A). Using these opened-loop SLI RNAs, an increase of one order of magnitude in $K_{D}$ was measured for the VS ribozyme/SLI interaction when replacing the preshifted SLI by the comparable shiftable SLI (Zamel and Collins 2002). The concordance with our results is particularly noteworthy given that these VS ribozyme/SLI complexes were artificially stabilized by an intermolecular helix (Zamel and Collins 2002). Moreover, it confirms that only SLV and not other parts of the VS ribozyme contribute to shifting the SLI helix upon SLI binding.

The energetic cost for shifting the SLI helix further increases when forming the SLI/SLV complex in the presence of stem Ia. Using shiftable SLI substrates, we observed a fivefold decrease in $K_{D}(\Delta \Delta G=1.0 \mathrm{kcal} / \mathrm{mol})$ for the SLI/SLV complex when replacing a shiftable SLI containing stem Ia (SLIsb) by a comparable SLI lacking stem Ia (SLIsb $\Delta I a)$. In contrast, no significant change in $K_{D}$ values was observed for SLI/SLV complexes formed by preshifted SLI substrates with (SLIps) or without (SLIps $\Delta \mathrm{Ia})$ stem Ia. These results are consistent with chemical modification and mutational studies in which the stem Ia was shown to be an inhibitory element of shiftable substrates for catalysis of self-cleaving ribozymes (Beattie and Collins 1997; Rastogi and Collins 1998; McLeod and Lilley 2004; Poon et al. 2006). However, it was not possible to conclude from these studies whether the disruption of helix Ia affected formation of the SLI/SLV interaction or other aspect(s) of catalysis. Particularly, mutations that disrupt stem Ia also increase the size of the linker between SLI and the rest of the ribozyme, and longer linkers have been associated with faster cleavage of self-cleaving ribozymes (Poon et al. 2006). Our thermodynamic results clearly indicate that the presence of stem Ia destabilizes the SLI/SLV interaction of shiftable SLI substrates but has no effect on preshifted SLI substrates. With the SLI and SLV variants used here, formation of the SLI/SLV complex with a preshifted SLI substrate containing stem Ia (SLIps) is more energetically favorable by $\sim 3 \mathrm{kcal} / \mathrm{mol}$ than with a shiftable SLI substrate containing stem Ia. In summary, stem Ia clearly contributes to stabilizing the unshifted inactive conformation and can affect cleavage rates of VS ribozymes when formation of the I/V interaction is rate limiting, as is likely the case for the wild-type self-cleaving ribozyme.

\section{The I/V kissing-loop interaction defines substrate recognition by the VS ribozyme}

The strong correlation observed between the thermodynamic and kinetic properties of several SLV variants supports the concept that the I/V kissing-loop interaction is a functionally modular unit for substrate recognition by the VS ribozyme. Structurally, the kissing-loop interaction forms an independent unit that is distinct from residues involved in cleavage chemistry (Hiley and Collins 2001; Lafontaine et al. 2001a, 2002a; Lipfert et al. 2008). For cleavage to occur, the SLI 
internal loop must dock with the catalytic domain to form the active site (Lafontaine et al. 2001b, 2002b; Sood and Collins 2002; Jones and Strobel 2003; Zhao et al. 2005; Smith and Collins 2007; Wilson et al. 2007, 2010; Jaikaran et al. 2008), and we now know that such docking does not contribute significantly to ground-state substrate binding at least with the trans SLI substrate/ribozyme system investigated here. Rather, the I/V kissing-loop interaction is thermodynamically dominant for substrate recognition by the VS ribozyme. The remarkable stability of this interaction is modulated by $\mathrm{Mg}^{2+}$ concentration and SLI conformational shifting such that formation of the I/V kissing-loop can consequently directly regulate the VS ribozyme cleavage reaction.

\section{MATERIALS AND METHODS}

\section{Preparation of RNA for ITC studies}

The RNA hairpins used in this study, including the SLI and SLV variants (Fig. 2) as well as the TAR, TAR*, and Moloney Murine Leukemia virus (MMLV) H3-18 RNAs (Fig. 5), were synthesized in vitro with the T7 RNA polymerase using synthetic DNA templates (Integrated DNA Technologies) and purified as previously described (Campbell and Legault 2005). Two SLI variants (SLIps and SLIsb $\Delta \mathrm{Ia}$ ) (Fig. 2A) were also chemically synthesized (Integrated DNA Technologies) with a 2'-O-methyl modification at position G-1 (SLIps-1m and SLIsb $\Delta \mathrm{Ia}-1 \mathrm{~m}$ ) and purified as previously described (Campbell and Legault 2005). The Avapl ribozyme, herein named VS Rz (Fig. 1A), was synthesized from plasmid pAvaplVS derived from plasmid pAvapl (Lacroix-Labonté et al. 2012) to allow synthesis of the ribozyme with its substrate at the $3^{\prime}$ end. The transcription reaction was performed in vitro at $37^{\circ} \mathrm{C}$ using the pAvaplVS plasmid linearized with EcoRI, the T7 RNA polymerase, unlabeled NTPs, and $25 \mathrm{mM} \mathrm{MgCl}_{2}$. After $3 \mathrm{~h}, 15 \mathrm{mM} \mathrm{MgCl}_{2}$ was added and the reaction mixture was incubated for $1 \mathrm{~h}$ to allow self-cleavage of the VS substrate. The cleavage reaction was stopped by addition of $40 \mathrm{mM}$ EDTA, and then the VS Rz was purified as previously described (Bouchard et al. 2008). Purified RNA samples were transferred to ITC buffers by use of Amicon Ultra- $43 \mathrm{~K}$ ultrafiltration devices: ITC buffer A ( $10 \mathrm{mM}$ Tris $\mathrm{pH}$ 7.0) for experiments with SLIps and SLV variants (Fig. 4; Table 1), TAR, TAR*, and MMLV H3-18 RNAs (Table 4) or ITC buffer B (10 mM Tris $\mathrm{pH} 7.0$ and $50 \mathrm{mM} \mathrm{NaCl}$ ) for experiments with SLV and SLI variants (Table 3 ) and VS Rz (Table 5). Prior to use, the RNAs were refolded by heating $\left(2 \mathrm{~min}\right.$ at $95^{\circ} \mathrm{C}$ for RNA hairpins or at $37^{\circ} \mathrm{C}$ for the VS Rz) and cooling in ice water. The RNA samples were subsequently transferred to ITC buffer supplemented with $\mathrm{MgCl}_{2}$, generally $20 \mathrm{mM} \mathrm{MgCl}_{2}$, although other $\mathrm{MgCl}_{2}$ concentrations were used to investigate the $\mathrm{Mg}^{2+}$ ion dependence of the I/V kissing-loop interaction. The $\mathrm{pH}$ of the Tris buffer was adjusted at room temperature. RNA concentrations were estimated from UV absorbance at $260 \mathrm{~nm}\left(\mathrm{~A}_{260}\right)$ using extinction coefficients $\left(\varepsilon_{260}\right)$ determined by taking the sum of $\varepsilon_{260}$ values for each nucleotide (Cavaluzzi and Borer 2004) within the RNA sequence and multiplying this sum by a hyperchromicity factor corresponding to the ratio of $\mathrm{A}_{260}$ values before and after Nuclease P1 digestion (Zaug et al. 1988; Legault 1995).

\section{Isothermal titration calorimetry (ITC) studies}

ITC measurements were performed at $25^{\circ} \mathrm{C}$ using a VP-ITC or ITC $_{200}$ Microcalorimeter (GE Healthcare). All solutions used with the VP-ITC were degassed for $10-15 \mathrm{~min}$ at $22^{\circ} \mathrm{C}$ before each experiment. For ITC titrations with SLV variants (Table 1), the concentrations of the SLV titrants in the injection syringe were $100 \mu \mathrm{M}$ (wildtype, U700C, and U695G SLV RNAs), $300 \mu \mathrm{M}$ ( $\Delta$ U700 and C699G SLV RNAs), or $1 \mathrm{mM}$ ( $\triangle \mathrm{U} 700$ and C699G SLV RNAs); and the concentration of SLIps in the cell was 10 times lower than that of the titrants, except for the titration with $300 \mu \mathrm{M}$ of $\Delta \mathrm{U} 700$ and C699G SLV RNAs in which $20 \mu \mathrm{M}$ of SLIps was used in the cell. For ITC titrations with SLI variants (Table 3), the concentrations of the SLI titrants in the syringe were $100 \mu \mathrm{M}$ (SLIps $\Delta \mathrm{Ia}$ and SLIds1 RNAs), $200 \mu \mathrm{M}$ (SLIsb $\Delta \mathrm{Ia}$, SLIps, SLIsb, and SLIds2 RNAs), or $600 \mu \mathrm{M}$ (SLIsb RNA); and the concentration of SLV in the cell was 10 times lower than that of the titrants. For ITC titrations with the VS ribozyme catalytic domain (VS Rz) (Table 5), the concentration of VS Rz in the syringe was $100 \mu \mathrm{M}$, and the concentration of noncleavable SLI (SLIsb $\Delta \mathrm{Ia}-1 \mathrm{~m}$ and SLIps-1m) (Table 5) in the cell was $10 \mu \mathrm{M}$. For ITC titration studies of the TAR/TAR* kissing-loop interaction (Table 4), the concentration of TAR RNA in the syringe was $50 \mu \mathrm{M}$, and the concentration of

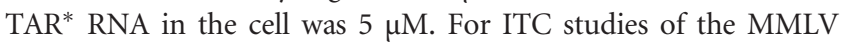
H3-18 kissing-loop dimer (Table 4), dilution experiments were performed with $500 \mu \mathrm{M}$ MMLV H3-18 hairpin in the syringe and buffer only in the cell.

Most ITC titrations were collected with $c$ values $\geq 1(c=$ [RNA in the cell $] / K_{D} ; c$ values between 2 and 850 ), from which accurate thermodynamic parameters were extracted (Wiseman et al. 1989; Turnbull and Daranas 2003). For titration data collected with $c$ values $<1 \quad(c=0.3$ and $c=0.6$ for complexes SLIps/SLVC699G and SLIsb/SLV, respectively), the stoichiometry $(n)$ was fixed to 1 , such that only $K_{\mathrm{A}}$ and $\Delta G$ could be accurately determined (Turnbull and Daranas 2003). For each titration experiment, a control experiment was performed under the same conditions, except that only buffer was used in the cell. The control experiment was subtracted from the titration experiment in order to eliminate the effect of diluting the titrant. Data collected for each titration experiment were then fit to a single binding site model or to a dimer-monomer dissociation model (for MMLV H3-18 only) using equations from the ORIGIN software package version 7.0 (OriginLab Corporation). The quality of the fits was obtained from the square of the correlation coefficient $\left(R^{2}\right)$, and in all cases $R^{2}$ was $\geq 0.99$. The values of $n$, $K_{A}$ (or $K_{D}=1 / K_{A}$ ), and $\Delta H$ were directly obtained from these fits. The free energy $\left(\Delta G_{I T C}\right)$ was calculated as $\Delta G_{I T C}=-R T \ln K_{A}$, where $R$ denotes the gas constant $\left(R=1.987 \mathrm{cal} \cdot \mathrm{mol}^{-1} \cdot \mathrm{K}^{-1}\right)$ and $T$ is the temperature. The values of $T \Delta S$ were derived from that of $\Delta G$ and $\Delta H$, given that $\Delta G=\Delta H-T \Delta S$. At least two ITC experiments were collected for each measurement. The reported values and errors on the thermodynamic parameters are, respectively, the average and standard deviations from these multiple measurements.

\section{ACKNOWLEDGMENTS}

We thank Elyse Benoit, Dominique Chaussé, Étienne Beaulieu, and Pierre Dagenais for RNA preparation; Ao Yang for help with ITC data analysis; and James G. Omichinski for critical reading of the manuscript. This work was supported by the Canadian Institutes of Health Research (CIHR) to P.L. [MOP-86502]. P.B. was 
supported by a Frederick Banting and Charles Best Canada Graduate Scholarship PhD scholarship from CIHR and graduate scholarships from the Université de Montréal. The ITC instruments were purchased with funds from the Natural Sciences and Engineering Research Council of Canada. P.L. holds a Canada Research Chair in Structural Biology and Engineering of RNA.

Received April 28, 2014; accepted June 3, 2014.

\section{REFERENCES}

Andersen A, Collins RA. 2000. Rearrangement of a stable RNA secondary structure during VS ribozyme catalysis. Mol Cell 5: 469478.

Andersen AA, Collins RA. 2001. Intramolecular secondary structure rearrangement by the kissing interaction of the Neurospora VS ribozyme. Proc Natl Acad Sci 98: 7730-7735.

Baranov PV, Henderson CM, Anderson CB, Gesteland RF, Atkins JF, Howard MT. 2005. Programmed ribosomal frameshifting in decoding the SARS-CoV genome. Virology 332: 498-510.

Batey RT, Gilbert SD, Montange RK. 2004. Structure of a natural guanine-responsive riboswitch complexed with the metabolite hypoxanthine. Nature 432: 411-415.

Beattie TL, Collins RA. 1997. Identification of functional domains in the self-cleaving Neurospora VS ribozyme using damage selection. J Mol Biol 267: 830-840.

Beattie TL, Olive JE, Collins RA. 1995. A secondary-structure model for the self-cleaving region of Neurospora VS RNA. Proc Natl Acad Sci 92: 4686-4690.

Blouin S, Lafontaine DA. 2007. A loop-loop interaction and a K-turn motif located in the lysine aptamer domain are important for the riboswitch gene regulation control. RNA 13: 1256-1267.

Bouchard P, Legault P. 2014. Structural insights into substrate recognition by the Neurospora Varkud satellite ribozyme: importance of U-turns at the kissing-loop junction. Biochemistry 53: 258-269.

Bouchard P, Lacroix-Labonté J, Desjardins G, Lampron P, Lisi V, Lemieux S, Major F, Legault P. 2008. Role of SLV in SLI substrate recognition by the Neurospora VS ribozyme. RNA 14: 736-748.

Brantl S. 2007. Regulatory mechanisms used by cis-encoded antisense RNAs. Curr Opin Microbiol 10: 102-109.

Brunel C, Marquet R, Romby P, Ehresmann C. 2002. RNA loop-loop interactions as dynamic functional motifs. Biochimie 84: 925-944.

Campbell DO, Legault P. 2005. NMR structure of the Varkud satellite ribozyme stem-loop V RNA and magnesium-ion binding from chemical-shift mapping. Biochemistry 44: 4157-4170.

Campbell DO, Bouchard P, Desjardins G, Legault P. 2006. NMR structure of Varkud satellite ribozyme stem-loop V in the presence of magnesium ions and localization of metal-binding sites. Biochemistry 45: 10591-10605.

Cavaluzzi MJ, Borer PN. 2004. Revised UV extinction coefficients for nucleoside-5'-monophosphates and unpaired DNA and RNA. Nucleic Acids Res 32: e13.

Chang KY, Tinoco I Jr. 1997. The structure of an RNA "kissing" hairpin complex of the HIV TAR hairpin loop and its complement. J Mol Biol 269: 52-66.

Chen AA, Garcia AE. 2012. Mechanism of enhanced mechanical stability of a minimal RNA kissing complex elucidated by nonequilibrium molecular dynamics simulations. Proc Natl Acad Sci 109: E1530E1539.

Chi YI, Martick M, Lares M, Kim R, Scott WG, Kim SH. 2008. Capturing hammerhead ribozyme structures in action by modulating general base catalysis. PLoS Biol 6: e234.

De la Peña M, Gago S, Flores R. 2003. Peripheral regions of natural hammerhead ribozymes greatly increase their self-cleavage activity. EMBO J 22: 5561-5570.

Draper DE. 2008. RNA folding: thermodynamic and molecular descriptions of the roles of ions. Biophys J 95: 5489-5495.
Ducongé F, Di Primo C, Toulmé JJ. 2000. Is a closing “GA pair” a rule for stable loop-loop RNA complexes? J Biol Chem 275: 21287-21294.

Dufour D, de la Peña M, Gago S, Flores R, Gallego J. 2009. Structurefunction analysis of the ribozymes of chrysanthemum chlorotic mottle viroid: a loop-loop interaction motif conserved in most natural hammerheads. Nucleic Acids Res 37: 368-381.

Ennifar E, Walter P, Ehresmann B, Ehresmann C, Dumas P. 2001. Crystal structures of coaxially stacked kissing complexes of the HIV-1 RNA dimerization initiation site. Nat Struct Biol 8: 1064-1068.

Flinders J, Dieckmann T. 2001. A pH controlled conformational switch in the cleavage site of the VS ribozyme substrate RNA. J Mol Biol 308: 665-679.

Franch T, Gerdes K. 2000. U-turns and regulatory RNAs. Curr Opin Microbiol 3: 159-164.

Franch T, Petersen M, Wagner EGH, Jacobsen JP, Gerdes K. 1999. Antisense RNA regulation in prokaryotes: rapid RNA/RNA interaction facilitated by a general U-turn loop structure. J Mol Biol 294: $1115-1125$.

Garst AD, Heroux A, Rambo RP, Batey RT. 2008. Crystal structure of the lysine riboswitch regulatory mRNA element. J Biol Chem 283: 22347-22351.

Gregorian RS Jr, Crothers DM. 1995. Determinants of RNA hairpin loop-loop complex stability. J Mol Biol 248: 968-984.

Grosjean H, Söll DG, Crothers DM. 1976. Studies of the complex between transfer RNAs with complementary anticodons. I. Origins of enhanced affinity between complementary triplets. J Mol Biol 103: 499-519.

Guo L, Allen EM, Miller WA. 2001. Base-pairing between untranslated regions facilitates translation of uncapped, nonpolyadenylated viral RNA. Mol Cell 7: 1103-1109.

Hiley SL, Collins RA. 2001. Rapid formation of a solvent-inaccessible core in the Neurospora Varkud satellite ribozyme. EMBO J 20: 5461-5469.

Hiley SL, Sood VD, Fan J, Collins RA. 2002. 4-thio-U cross-linking identifies the active site of the VS ribozyme. EMBO J 21: 4691-4698.

Hoffmann B, Mitchell GT, Gendron P, Major F, Andersen AA, Collins RA, Legault P. 2003. NMR structure of the active conformation of the Varkud satellite ribozyme cleavage site. Proc Natl Acad Sci 100: 7003-7008.

Jaikaran D, Smith MD, Mehdizadeh R, Olive J, Collins RA. 2008. An important role of G638 in the cis-cleavage reaction of the Neurospora VS ribozyme revealed by a novel nucleotide analog incorporation method. RNA 14: 938-949.

Jones FD, Strobel SA. 2003. Ionization of a critical adenosine residue in the Neurospora Varkud satellite ribozyme active site. Biochemistry 42: 4265-4276.

Khvorova A, Lescoute A, Westhof E, Jayasena SD. 2003. Sequence elements outside the hammerhead ribozyme catalytic core enable intracellular activity. Nat Struct Biol 10: 708-712.

Kim CH, Tinoco I Jr. 2000. A retroviral RNA kissing complex containing only two G-C base pairs. Proc Natl Acad Sci 97: 9396-9401.

Lacroix-Labonté J, Girard N, Lemieux S, Legault P. 2012. Helix-length compensation studies reveal the adaptability of the VS ribozyme architecture. Nucleic Acids Res 40: 2284-2293.

Lafontaine DA, Norman DG, Lilley DM. 2001a. Structure, folding and activity of the VS ribozyme: importance of the 2-3-6 helical junction. EMBO J 20: 1415-1424.

Lafontaine DA, Wilson TJ, Norman DG, Lilley DM. 2001b. The A730 loop is an important component of the active site of the VS ribozyme. J Mol Biol 312: 663-674.

Lafontaine DA, Norman DG, Lilley DM. 2002a. The global structure of the VS ribozyme. EMBO J 21: 2461-2471.

Lafontaine DA, Wilson TJ, Zhao ZY, Lilley DMJ. 2002b. Functional group requirements in the probable active site of the VS ribozyme. J Mol Biol 323: 23-34.

Lebars I, Legrand P, Aimé A, Pinaud N, Fribourg S, Di Primo C. 2008. Exploring TAR-RNA aptamer loop-loop interaction by X-ray crystallography, UV spectroscopy and surface plasmon resonance. Nucleic Acids Res 36: 7146-7156. 
Lee AJ, Crothers DM. 1998. The solution structure of an RNA loop-loop complex: the ColE1 inverted loop sequence. Structure 6: 993-1005.

Legault P. 1995. Structural studies of ribozymes by heteronuclear NMR spectroscopy. University of Colorado at Boulder, Boulder, CO.

Leipply D, Lambert D, Draper DE. 2009. Ion-RNA interactions: thermodynamic analysis of the effects of mono- and divalent ions on RNA conformational equilibria. Methods Enzymol 469B: 433-463.

Lemay JF, Penedo JC, Tremblay R, Lilley DM, Lafontaine DA. 2006 Folding of the adenine riboswitch. Chem Biol 13: 857-868.

Li PT, Bustamante C, Tinoco I Jr. 2006. Unusual mechanical stability of a minimal RNA kissing complex. Proc Natl Acad Sci 103: 1584715852.

Lipfert J, Ouellet J, Norman DG, Doniach S, Lilley DM. 2008. The complete VS ribozyme in solution studied by small-angle X-ray scattering. Structure 16: 1357-1367.

Lorenz C, Piganeau N, Schroeder R. 2006. Stabilities of HIV-1 DIS type RNA loop-loop interactions in vitro and in vivo. Nucleic Acids Res 34: 334-342.

Marky LA, Breslauer KJ. 1987. Calculating thermodynamic data for transitions of any molecularity from equilibrium melting curves. Biopolymers 26: 1601-1620.

McLeod AC, Lilley DM. 2004. Efficient, pH-dependent RNA ligation by the VS ribozyme in trans. Biochemistry 43: 1118-1125.

Michiels PJA, Schouten CHJ, Hilbers CW, Heus HA. 2000. Structure of the ribozyme substrate hairpin of Neurospora VS RNA: a close look at the cleavage site. RNA 6: 1821-1832.

Moras D, Dock AC, Dumas P, Westhof E, Romby P, Ebel JP, Giege R. 1986. Anticodon-anticodon interaction induces conformational changes in tRNA: yeast tRNA ${ }^{\text {Asp }}$, a model for tRNA-mRNA recognition. Proc Natl Acad Sci 83: 932-936.

Nair TM, Myszka DG, Davis DR. 2000. Surface plasmon resonance kinetic studies of the HIV TAR RNA kissing hairpin complex and its stabilization by 2 -thiouridine modification. Nucleic Acids Res 28 1935-1940.

Ogle JM, Brodersen DE, Clemons WM Jr, Tarry MJ, Carter AP, Ramakrishnan V. 2001. Recognition of cognate transfer RNA by the 30 S ribosomal subunit. Science 292: 897-902.

Poon AH, Olive JE, McLaren M, Collins RA. 2006. Identification of separate structural features that affect rate and cation concentration dependence of self-cleavage by the Neurospora VS ribozyme. Biochemistry 45: 13394-13400.

Quigley GJ, Rich A. 1976. Structural domains of transfer RNA molecules. Science 194: 796-806.

Rastogi T, Collins RA. 1998. Smaller, faster ribozymes reveal the catalytic core of Neurospora VS RNA. J Mol Biol 277: 215-224.

Rastogi T, Beattie TL, Olive JE, Collins RA. 1996. A long-range pseudoknot is required for activity of the Neurospora VS ribozyme. EMBO J 15: $2820-2825$.

Reymond C, Bisaillon M, Perreault JP. 2009. Monitoring of an RNA multistep folding pathway by isothermal titration calorimetry. Biophys J 96: 132-140.

Salim NN, Feig AL. 2009. Isothermal titration calorimetry of RNA. Methods 47: 198-205.

Serganov A, Yuan YR, Pikovskaya O, Polonskaia A, Malinina L, Phan AT, Hobartner C, Micura R, Breaker RR, Patel DJ. 2004. Structural basis for discriminative regulation of gene expression by adenine- and guanine-sensing mRNAs. Chem Biol 11: 1729-1741.

Serganov A, Huang L, Patel DJ. 2008. Structural insights into amino acid binding and gene control by a lysine riboswitch. Nature 455: $1263-1267$.
Serra MJ, Turner DH. 1995. Predicting thermodynamic properties of RNA. Methods Enzymol 259: 242-261.

Skripkin E, Paillart JC, Marquet R, Ehresmann B, Ehresmann C. 1994. Identification of the primary site of the human immunodeficiency virus type 1 RNA dimerization in vitro. Proc Natl Acad Sci 91: 4945-4949.

Smith MD, Collins RA. 2007. Evidence for proton transfer in the ratelimiting step of a fast-cleaving Varkud satellite ribozyme. Proc Natl Acad Sci 104: 5818-5823.

Sood VD, Collins RA. 2002. Identification of the catalytic subdomain of the VS ribozyme and evidence for remarkable sequence tolerance in the active site loop. J Mol Biol 320: 443-454.

Sood VD, Beattie TL, Collins RA. 1998. Identification of phosphate groups involved in metal binding and tertiary interactions in the core of the Neurospora VS ribozyme. J Mol Biol 282: 741-750.

Turnbull WB, Daranas AH. 2003. On the value of $c$ : Can low affinity systems be studied by isothermal titration calorimetry? J Am Chem Soc 125: 14859-14866.

Van Melckebeke H, Devany M, Di Primo C, Beaurain F, Toulmé JJ, Bryce DL, Boisbouvier J. 2008. Liquid-crystal NMR structure of HIV TAR RNA bound to its SELEX RNA aptamer reveals the origins of the high stability of the complex. Proc Natl Acad Sci 105: 9210-9215.

Wagner EG, Simons RW. 1994. Antisense RNA control in bacteria, phages, and plasmids. Annu Rev Microbiol 48: 713-742.

Weixlbaumer A, Werner A, Flamm C, Westhof E, Schroeder R. 2004. Determination of thermodynamic parameters for HIV DIS type loop-loop kissing complexes. Nucleic Acids Res 32: 51265133.

Westhof E, Dumas P, Moras D. 1988. Restrained refinement of two crystalline forms of yeast aspartic acid and phenylalanine transfer RNA crystals. Acta Crystallogr A 44 (Pt 2): 112-123.

Wilson TJ, McLeod AC, Lilley DM. 2007. A guanine nucleobase important for catalysis by the VS ribozyme. EMBO J 26: 24892500.

Wilson TJ, Li NS, Lu J, Frederiksen JK, Piccirilli JA, Lilley DM. 2010. Nucleobase-mediated general acid-base catalysis in the Varkud satellite ribozyme. Proc Natl Acad Sci 107: 11751-11756.

Wiseman T, Williston S, Brandts JF, Lin LN. 1989. Rapid measurement of binding constants and heats of binding using a new titration calorimeter. Anal Biochem 179: 131-137.

Xia T, SantaLucia J Jr, Burkard ME, Kierzek R, Schroeder SJ, Jiao X, Cox C, Turner DH. 1998. Thermodynamic parameters for an expanded nearest-neighbor model for formation of RNA duplexes with Watson-Crick base pairs. Biochemistry 37: 14719-14735.

Zamel R, Collins RA. 2002. Rearrangement of substrate secondary structure facilitates binding to the Neurospora VS ribozyme. J Mol Biol 324: 903-915.

Zamel R, Poon A, Jaikaran D, Andersen A, Olive J, De Abreu D, Collins RA. 2004. Exceptionally fast self-cleavage by a Neurospora Varkud satellite ribozyme. Proc Natl Acad Sci 101: 14671472.

Zaug AJ, Grosshans CA, Cech TR. 1988. Sequence-specific endoribonuclease activity of the Tetrahymena ribozyme: enhanced cleavage of certain oligonucleotide substrates that form mismatched ribozyme-substrate complexes. Biochemistry 27: 8924-8931.

Zhao ZY, McLeod A, Harusawa S, Araki L, Yamaguchi M, Kurihara T, Lilley DM. 2005. Nucleobase participation in ribozyme catalysis. $J$ Am Chem Soc 127: 5026-5027. 

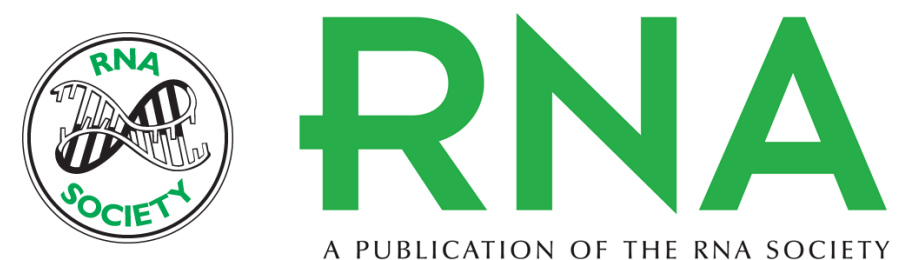

A PUBLICATION OF THE RNA SOCIETY

\section{A remarkably stable kissing-loop interaction defines substrate recognition by the Neurospora Varkud Satellite ribozyme}

Patricia Bouchard and Pascale Legault

RNA 2014 20: 1451-1464 originally published online July 22, 2014

Access the most recent version at doi:10.1261/rna.046144.114

$\begin{array}{ll}\text { References } & \begin{array}{l}\text { This article cites } 80 \text { articles, } 26 \text { of which can be accessed free at: } \\ \text { http://rnajournal.cshlp.org/content/20/9/1451.full.html\#ref-list-1 }\end{array}\end{array}$

Creative This article is distributed exclusively by the RNA Society for the first 12 months after the

Commons full-issue publication date (see http://rnajournal.cshlp.org/site/misc/terms.xhtml). After 12

License months, it is available under a Creative Commons License (Attribution-NonCommercial 4.0 International), as described at http://creativecommons.org/licenses/by-nc/4.0/.

Email Alerting Receive free email alerts when new articles cite this article - sign up in the box at the Service top right corner of the article or click here. 